\title{
Climatology of Guinea: Study of Climate Variability in
}

\section{N'zerekore}

\author{
Rene Tato Loua ${ }^{1,2,4}$, Maoro Beavogui ${ }^{1}$, Hassan Bencherif ${ }^{2,3}$, Alpha Boubacar Barry ${ }^{1}$, Zoumana Bamba ${ }^{4}$ and \\ Christine Amory-Mazaudier ${ }^{5,6}$ \\ 1. Guinea Weather Service (DNM), Conakry, BP 566, Guinea \\ 2. Laboratoire de l'Atmosphère et des Cyclones, Université de La Réunion, UMR 8105, CNRS, La Réunion, France \\ 3. School of Chemistry and Physics, University of KwaZulu-Natal, Westville, Durban, South Africa \\ 4. Scientific Research Center of Conakry Rogbane (CERESCOR), Conakry, BP 1615, Guinea \\ 5. Laboratoire de Physique du Plasma, Université Pierre et Marie Curie, UMR 7648, Paris, France \\ 6. International Center for Theoretical Physics (CTP), Strada Costiera 11, I-34151 Trieste, Italy
}

\begin{abstract}
N'zerekore is a geographical region of Guinea, which houses a weather observatory located at longitude $8.8^{\circ}$, latitude $7.7^{\circ}$ and altitude $475 \mathrm{~m}$. This region is of major socio-economic interest for the country. The climatological study of this region shows the variability of each parameter. The objective of this study was to analyze meteorological parameters trends and to assess the space-time evolution of some agro-climatic risks related to the main trends observed in the meteorological parameters regime of this region. In this study, programming tools were used for processing and analyzing meteorological parameters data, including temperatures, rains, wind, evaporation and storms measured in this observatory from 1931 to 2014. The interannual, annual and daily variations of these parameters were obtained, as well as temperature, precipitation anomalies and agroclimatic indexes trends. The analyzing of these variations explained that September is the rainiest months, and the year 1932, 1957 and 1970 are normal, rainy and dry year, respectively. The evaporation increased since 1971 from January to March and November to December. A positive temperature anomaly was observed since 1973 with the maximum $26-33{ }^{\circ} \mathrm{C}$ and the minimum $16-21{ }^{\circ} \mathrm{C}$. A dominant westerly wind with a speed of $2.6 \mathrm{~m} / \mathrm{s}$ was determined. Agro-climatic parameters in N'zerekore have high variability. From 1931 to 2014 , three major periods can be distinguished: a wet period from 1931 to 1977, a dry period from 1978 to 1994 and rainfall variability from 1995 to 2014. The trend of these parameters explains the impact of climate change in this part of the world. This is exacerbated by human activity (deforestation), thus mitigation measures are necessary. It would be useful to extend this study throughout the country.
\end{abstract}

Key words: Climate change, N'zerekore, agroclimatic index.

\section{Introduction}

Guinea is a country with great agro-sylvo-pastoral potential. Their exploitation requires an agricultural planning effort, which can not be done without a good understanding of the climate, especially the variability and distribution of rainfall [1]. Because of their immediate and lasting impact on the natural environment and man, the questions of climate change and variability (temperature and precipitation) are

Corresponding author: Rene Tato Loua, Ph.D. student, research fields: meteorlogy, physics of atmosphere, remote sensing, GIS and natural risks. placed for some time in the center of the concerns of scientists and policy makers in the world [2]. Climate change and variability issues have long been studied in large dimension, while results show that climates vary from one country to another and sometimes within the same country because of the existence of several different ecosystems [3].

The most important issue, especially for West Africa than in other regions of the world, is the study of climate change and variability at local scales, so that policy makers can adapt to any increase in risks and take advantage of any positive effect which might 
be resulted in [4].

In Guinea, precipitations are the most important climate parameter for both populations and ecosystems, and thus define different natural regions $[5,6]$. Consequently, the economy is mainly oriented towards the activities that depend on climate, including rainfall [7]. It is thus that in a context of great vulnerability and limited capacity, a slight change in rainfall patterns could instantly affect hundreds of thousands of vulnerable people who depend on rain to live [8]. The Guinea is composed of 33 prefectures, while this study is focused on N'zerekore prefecture (Fig. 1). Indeed, the population of N'zerekore is predominantly rural, and the performance of operated production systems (agriculture and livestock) is closely subject to climate.

The agroclimatic characteristics in any country or subnational region are primarily determined by intra-year distributions and inter-year variations in rainfall and temperature $[9,10]$.

However, the climate is rarely seen as a precious natural resource for economic and social growth until a major event disrupts energy production or agriculture or health risk of the population.
Agriculture is typically the most important sector in the economy of developing countries, especially in the least developed countries (LDCs) and small island developing states (SIDS). The practice of agriculture and the productivity of the agricultural systems depend heavily on prevailing rainfall and temperature patterns. So, the agricultural sector and other sectors are very vulnerable to climate change [11].

The semi-arid and sub-humid areas in West Africa possess highly variable and erratic rainfall which affects agricultural productivity. Agricultural practices have had to adapt to these climate risks, because very little land is irrigated. Consequently, any change in the current climate threatens agricultural productivity and the survival of many populations in West Africa.

Knowledge of the variability of these parameters is very important for the planning of agricultural activities. Also, knowing of agroclimatic characteristics can be used to strengthen the techniques of seasonal rainfall forecast and agro-climatic projections in the region. Thus, in this study, the programming tools were used to analyze and characterize the climate variability and agroclimatic parameters observed in N'zerekore synoptic station 1931 to 2014.

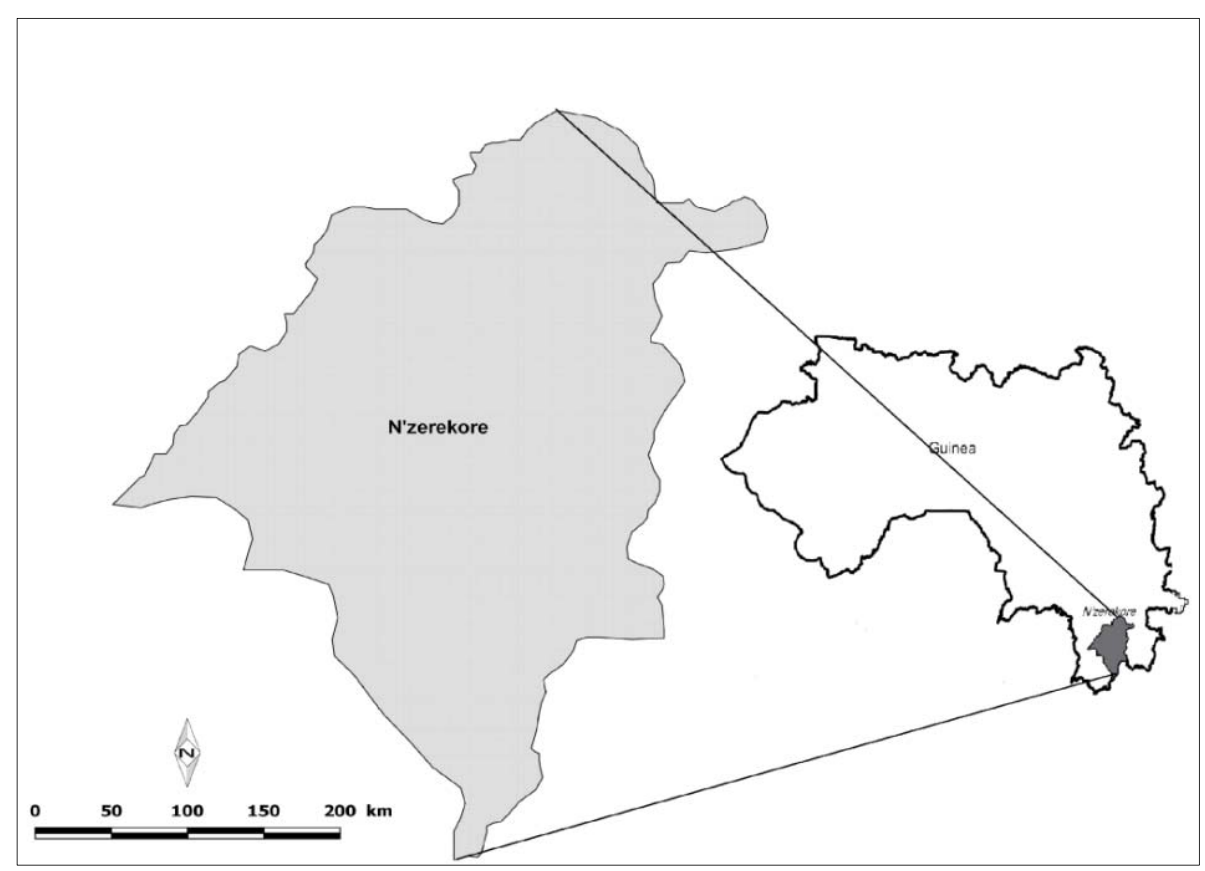

Fig. 1 Localization of N'zerekore in Guinea. 


\section{Materials and Methods}

In this study, the climatological data cover the period from 1931 to 2014, recorded by weather observatory of N'zerekore $\left(7.7^{\circ} \mathrm{N}, 8.8^{\circ} \mathrm{W}\right)$, and extracted from the well-preserved archives of Guinea National Weather Service.

Among the Guinea observatories, N'zerekore meteorological data are the subject of national, regional and global uses, so they were used for an international study [12]. As for the variability of agroclimatic parameters, the daily rainfall data from 1961 to 2013 of the synoptic observatory of N'zerekore were used.

The Informatics Centre of the National Weather Service has developed robust PC uses CLICOM software for managing its climate data. Other software, such as Climsoft, Excel, Word and INSTAT+, were used for data processing and presentation of results. Qgis were used for map editing. The observations of various meteorological elements did not start at the same time, and due to measurement interruptions for some data, calculated climatic parameters do not relate to the same period. But the minimum period recognized for describing the climate is 30 years according to World Meteorological Organization (WMO), and the period used is sufficient to consider an appreciable climate studies in N'zerekore.

The softness or harsh climate is confirmed by the variation of the observed values of climatic parameters in relation to the average during the period. Analysis of these variations and interpretations of the results are subject of the present work.

Statistical analysis of climatological data covers:

(1) Trend and variability of total rainfall and evaporation;

(2) Trend and variability of agroclimatic parameters. The main indexes or agroclimatic parameters studied are the start date of the growing season; end dates of the agricultural season; the length of the growing season; the length of dry spell observed in the fifty days after the start of the rainy season; the length of dry sequences of flowering (dry sequence observed during flowering-maturation); the number of rainfall days recorded during the growing season; the total rainfall of the growing season; heavy daily rainfall during the growing season;

(3) Trend and variability of the maximum and minimum temperature;

(4) Storms frequency;

(5) Wind speed and direction.

The average of 1961-1990 has being used as reference period in variability analysis of parameters.

\section{Results and Discussion}

\subsection{Major Temporal Trends in Rainfall Patterns}

3.1.1 Interannual Variation in 1931-2014

The analysis of the interannual variation of total rain shows two periods of oscillation around the normal value $(1,880 \mathrm{~mm})$ with a pitch of five years between 1931 and 2014 (Fig. 2). Deficit years (1969) are below the normal, surplus years (1957) are under the normal and years on the normal value are normal years (1932).

It should be noted that during the long period of 20 years of deficit, only the years 1989 and 1990 record a slight rainfall excess. The height varies between 1,473 $\mathrm{mm}$ and 2,539 $\mathrm{mm}$ in 1970 and 1957 with an average of $1,879 \mathrm{~mm}$. This result is consistent with that found by Bangoura [13].

3.1.2 Annual Variation in 1931-2014

N'zerekore rainfall is variable. The total rainfall of $1,878.7 \mathrm{~mm}$ is observed in $138 \mathrm{~d}$ in monthly average by year (Fig. 3). This is explained by the variability of wealth in steam generator of air mass in the rain through the area and the presence of mountains that promote the rise of the air mass.

The wet season lasts for 8-9 months. It begins in early March and ends in late November. The maximum value of rain in the year is observed in September $(325.1 \mathrm{~mm})$ with $20 \mathrm{~d}$ in average and the 


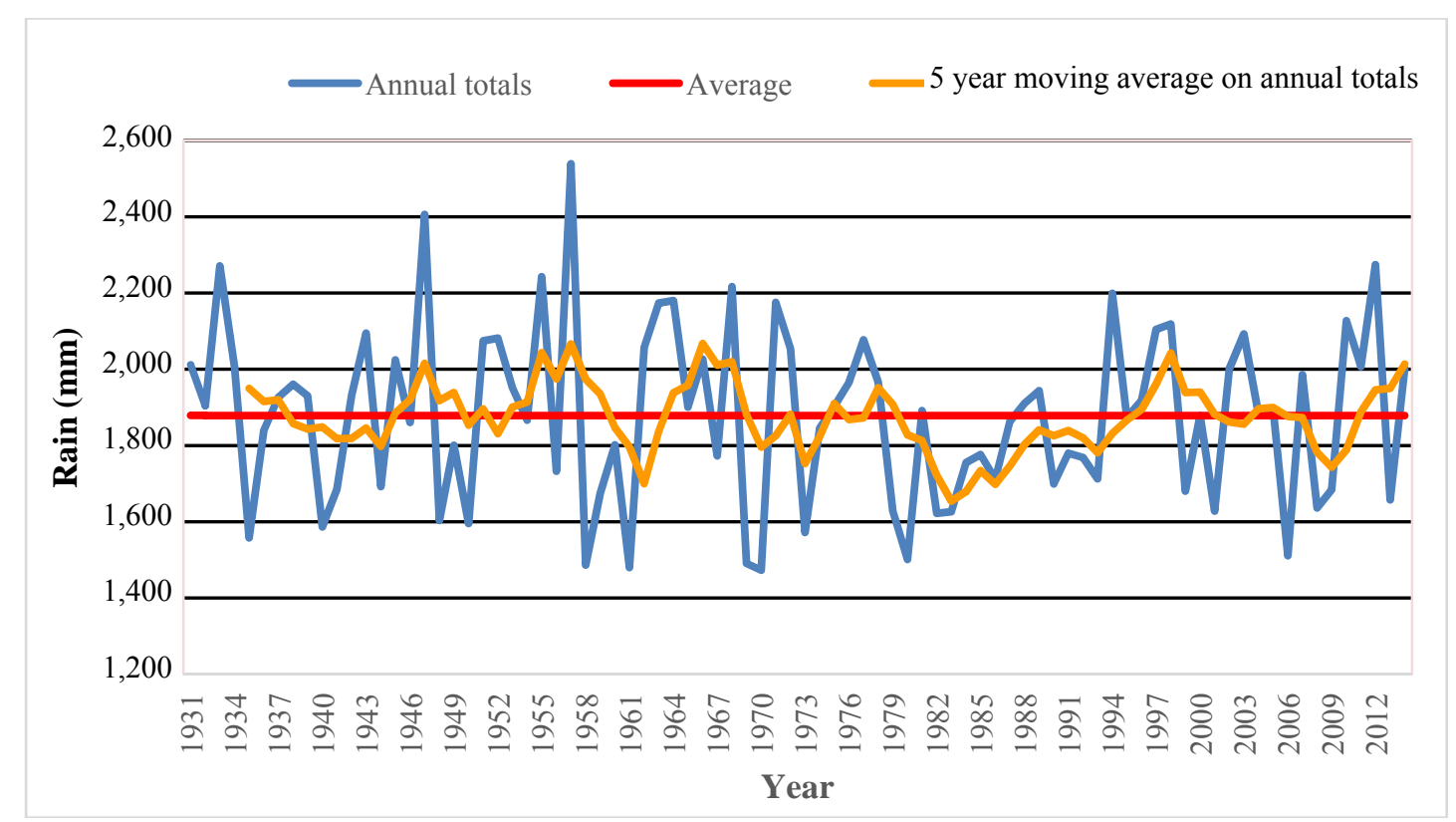

Fig. 2 Interannual rainfall variation in N'zerekore (1931-2014).

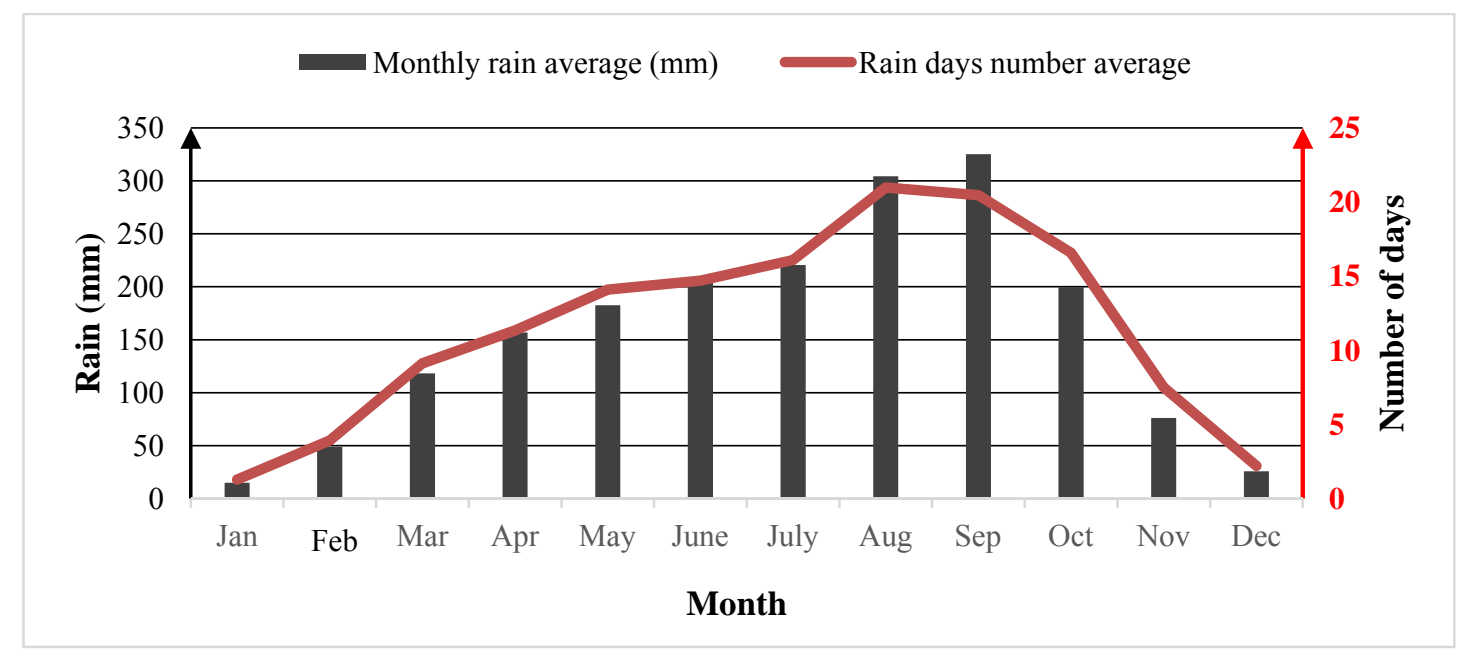

Fig. 3 Annual rainfall variation in N'zerekore (1931-2014).

minimum value in January $(14.9 \mathrm{~mm})$ with $1 \mathrm{~d}$ in average. During this month, more than $17.30 \%$ of the annual rainfall is observed. Annual distribution of rainfall and number of rainy days in N'zerekore from 1931 to 2014 show that the maximum rainfall occurs in September, but the most rain days are observed in August (21 d in average). For Guinea region, a significant warm water impact is only found in March (dry season) when precipitation is increased [14].

\subsubsection{Seasonal Total Rainfall Variation}

In N'zerekore, seasonal precipitation ranges from $98 \mathrm{~mm}$ to $850 \mathrm{~mm}$. The lowest seasonal totals are stored in the December-January-February (DJF) season, while the largest are registered in July-August-September (JAS) season.

The comparison of average 1961-1990 and 1981-2010 shows a decrease in seasonal total rainfall from the September-October-November (SON) to April-May-June (AMJ) season and an increase in seasonal total rainfall from May-June-July (MJJ) to August-September-October (ASO) season. This denotes an increase in rainfall totals in the period (season) and a decrease in rainfall amounts during market gardening periods. In average, the contribution 
of seasonal precipitations in the annual total rainfall varies between $98 \mathrm{~mm}$ (JAS) and $850 \mathrm{~mm}$ (DJF) for the time-series of 1931-2014 (Fig. 4).

The contribution of the seasonal total rainfall to annual rainfall in N'zerekore varies between $0 \%$ and $6 \%$ (Fig. 5). The greatest contribution is made in July-August-September (JAS) season and the smallest in December-January-February (DJF) season. Compared to the period of 1961-1990, there is a decline of seasonal totals contribution from September-October-November (SON) to April-May-June (AMJ) season and an increase from May-June-July (MJJ) to August-September-October (ASO) season for the period of 1981-2010.

\subsubsection{Daily Variation}

The daily precipitation is $147 \mathrm{~mm}$ recorded on October 12, 1925 in N'zerekore. The daily rainfall is highly variable in general. To characterize this high variability of daily rainfall, annual registration of daily rains is presented for the wettest year (1957), the driest year (1970) and a normal year (1932) (Figs. 6-8). According to these figures, the real rainy season starts from early March. But there is a clear difference between the driest year and the wettest year during and at the end of the rainy season. The rains are more frequent, more intense and longer in wet year (1957) than in dry year (1970).

The change in cumulative profiles around normal can predict whether a year will be deficit, normal or excess (Fig. 9).

Normal years 1931-2014, 1961-1990 and 1981-2010 have the same pace during the year. All curves follow normal until the 40th day. The forecast is not easy in this period. In 1932, since the 40th day, the curve undergoes a sudden increase in rainfall and remains above normal until the 201st day after a considerable drop or interruption of rains. It follows the normal from the 224th day until the end of the year. There is an increase of rain from the 74th day of the year 1957 , and cumulative curve remains above normal until the end of year.

As for 1970, it follows normal until the 182nd day and the curve decreases to remain below normal until the end of year. Analysis of these curves shows an important direction for the overall annual forecast of rainfall. If very early in the year daily precipitations yield above normal values, this may mean that this year will be excess or normal.

If follow normal rainfall up to about 4-5 months before decreasing, it indicates that this year will be in deficit. And if daily rainfalls stay below normal until about 2-3 months before it grows, this year will be

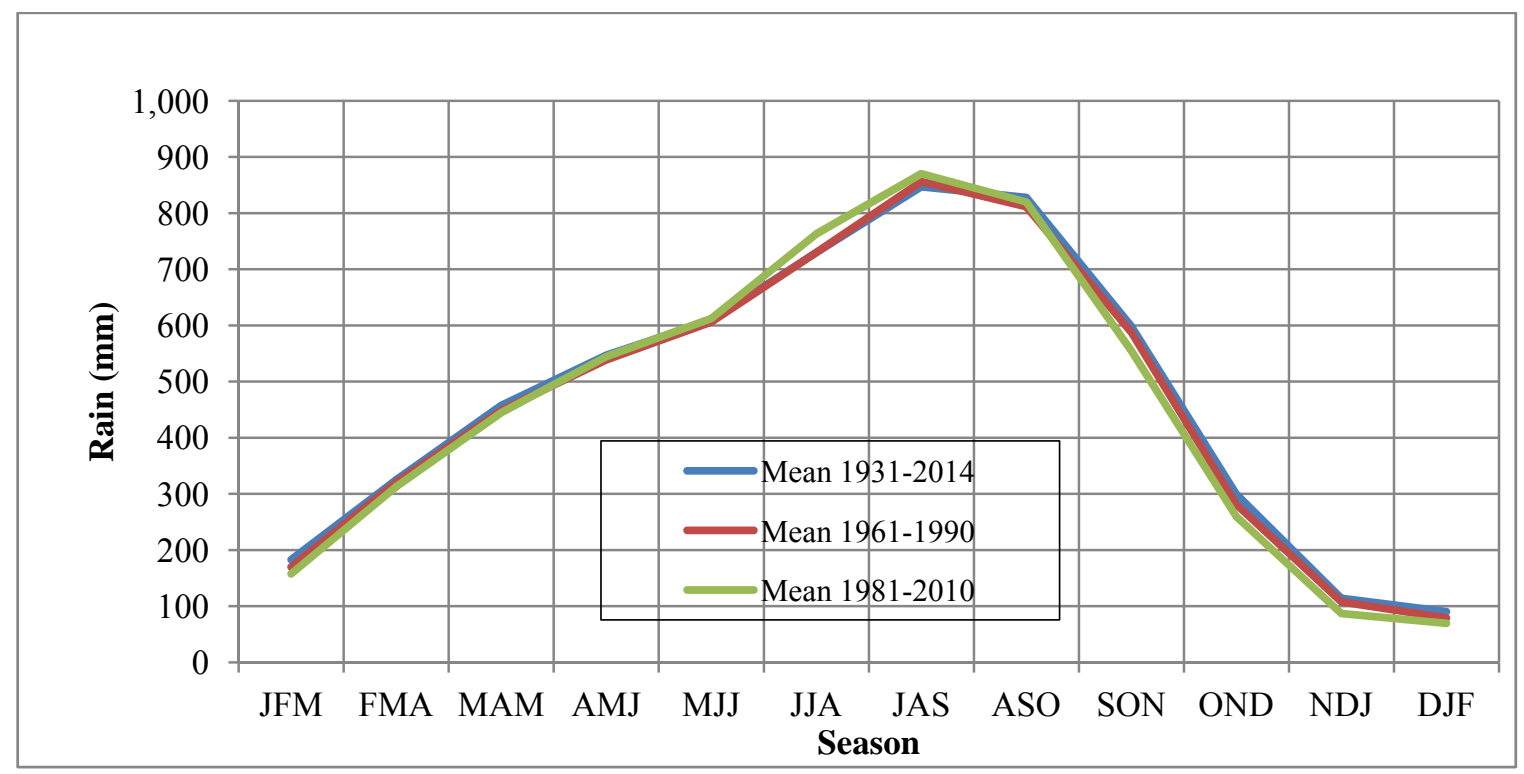

Fig. 4 Seasonal totals rain in N'zerekore. 


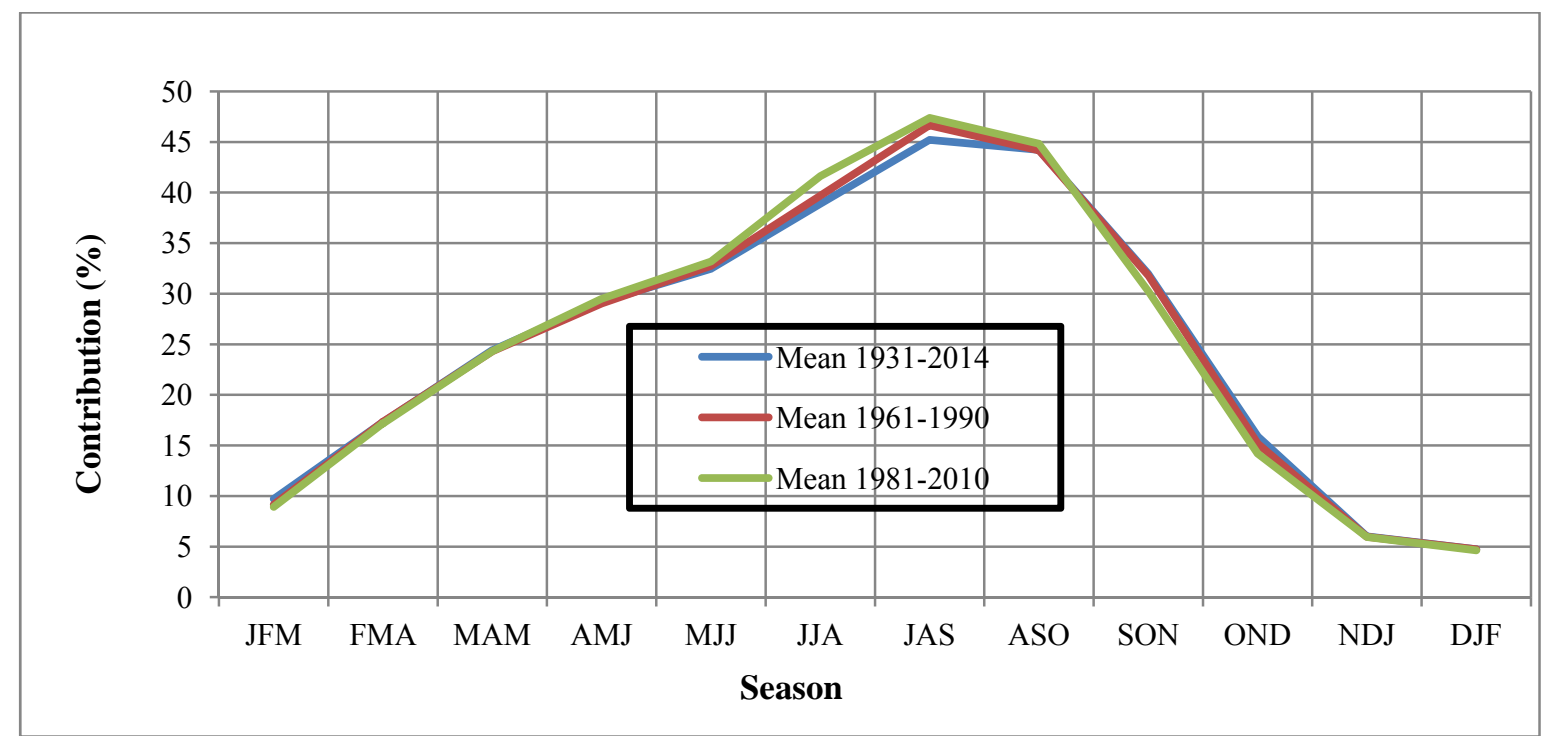

Fig. 5 Seasonal contributions to annual rainfall in N'zerekore.

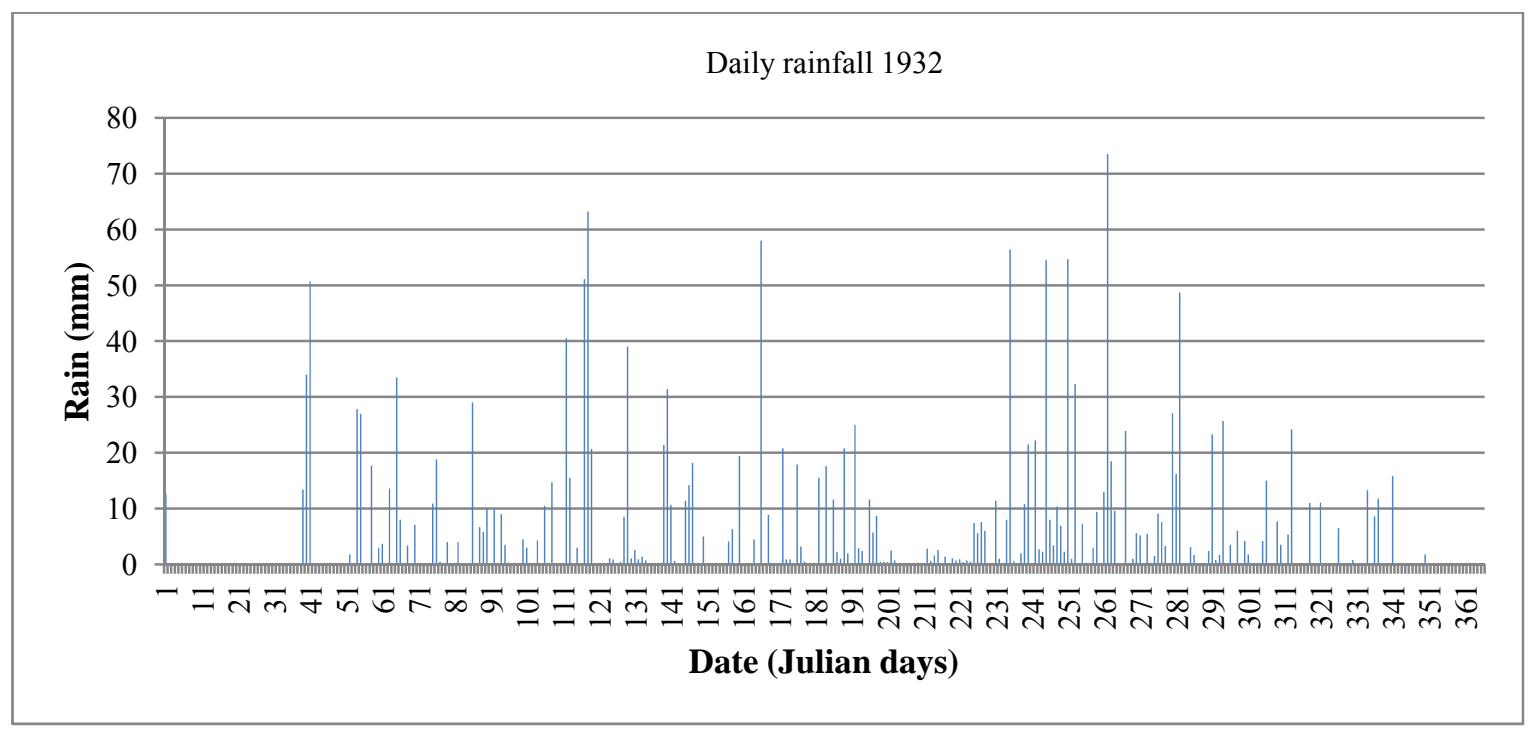

Fig. 6 Daily rainfall distribution in wet year 1957 (surplus year to mean of 1931-2014).

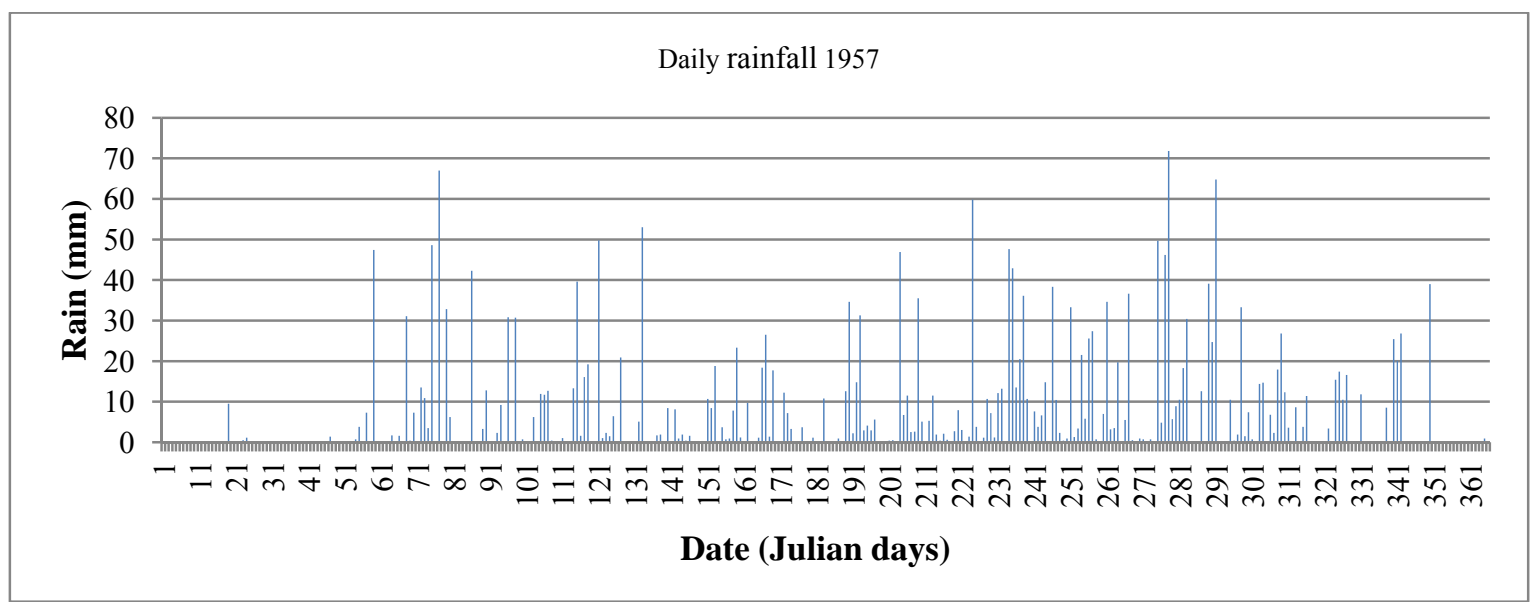

Fig. 7 Daily rainfall distribution in dry year 1970 (deficit year to mean of 1931-2014). 


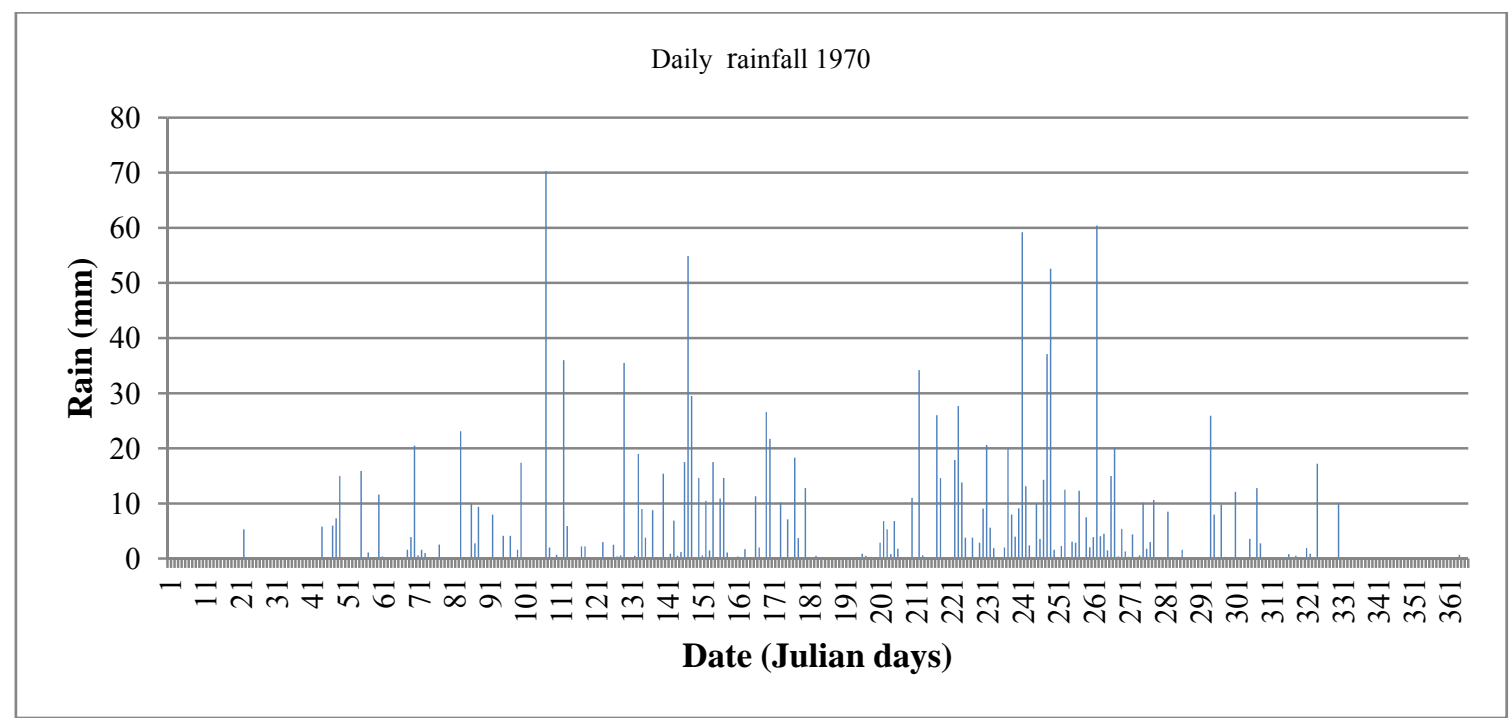

Fig. 8 Daily rainfall distribution in normal year 1932 (normal year to mean of 1931-2014).

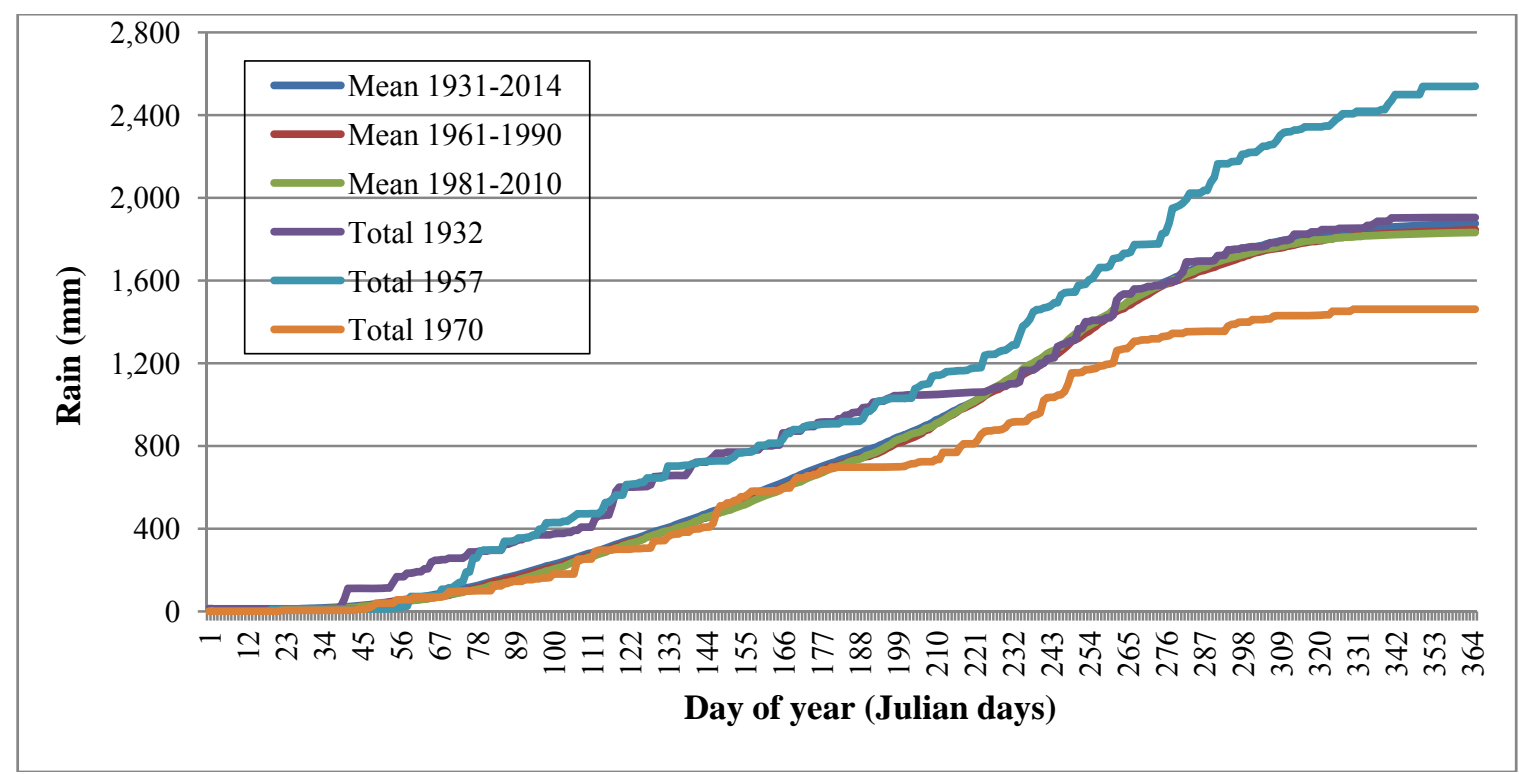

Fig. 9 Cumulative profiles.

normal. Analysis of the cumulative rainfall profile between the $35 \mathrm{~d}$ and $225 \mathrm{~d}$ in average predicts that the year will be normal, deficit or excess.

\subsection{Temperatures Trend and Variability}

The sun's energy is a power source that drives the earth's climate system. The knowledge of the climate system is based on the physical laws of emission and absorption of electromagnetic radiation and how these relate to incoming solar radiation and outgoing terrestrial radiation.
In theory, the earth's average surface temperature might be expected to be around $-19{ }^{\circ} \mathrm{C}$, much lower than the observed value of about $14^{\circ} \mathrm{C}$. The reason for this difference is the earth's atmosphere, which itself absorbs and re-emits energy. This naturally occurring process is commonly known as the greenhouse effect, which plays a significant role in setting the earth's surface and atmospheric temperatures [15].

The temperature of an area is essentially a form of manifestation of global radiation (solar and infrared) or the energy balance. 


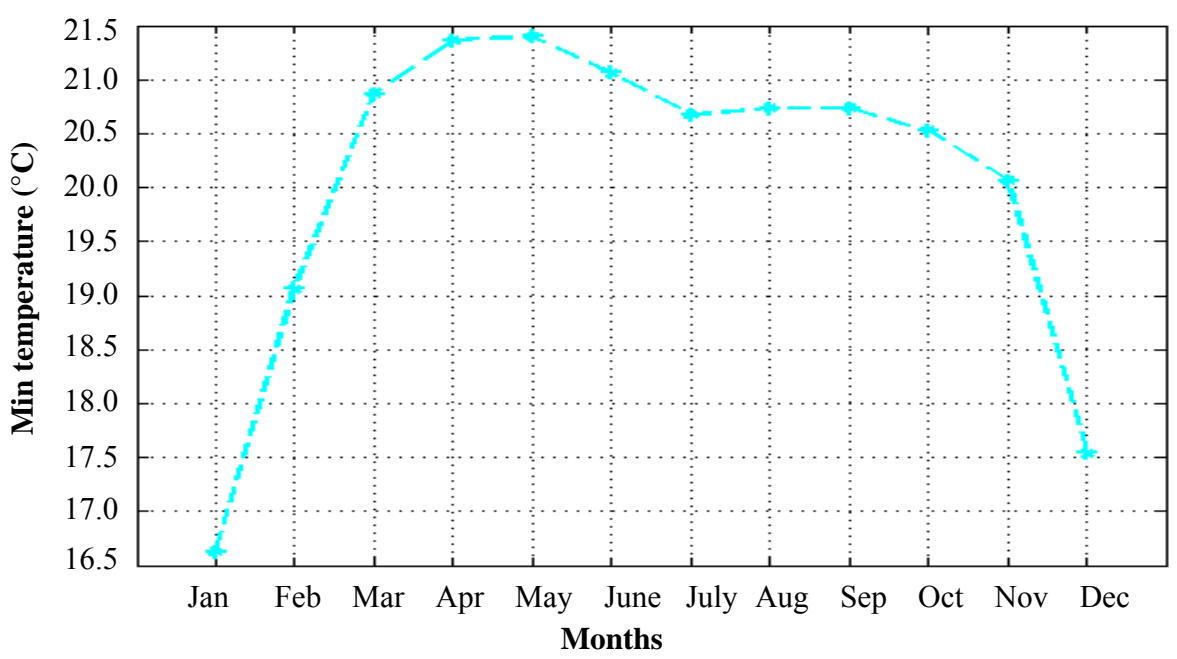

Fig. 10 Annual variation of the minimum temperature in 1981-2014 in N'zerekore.

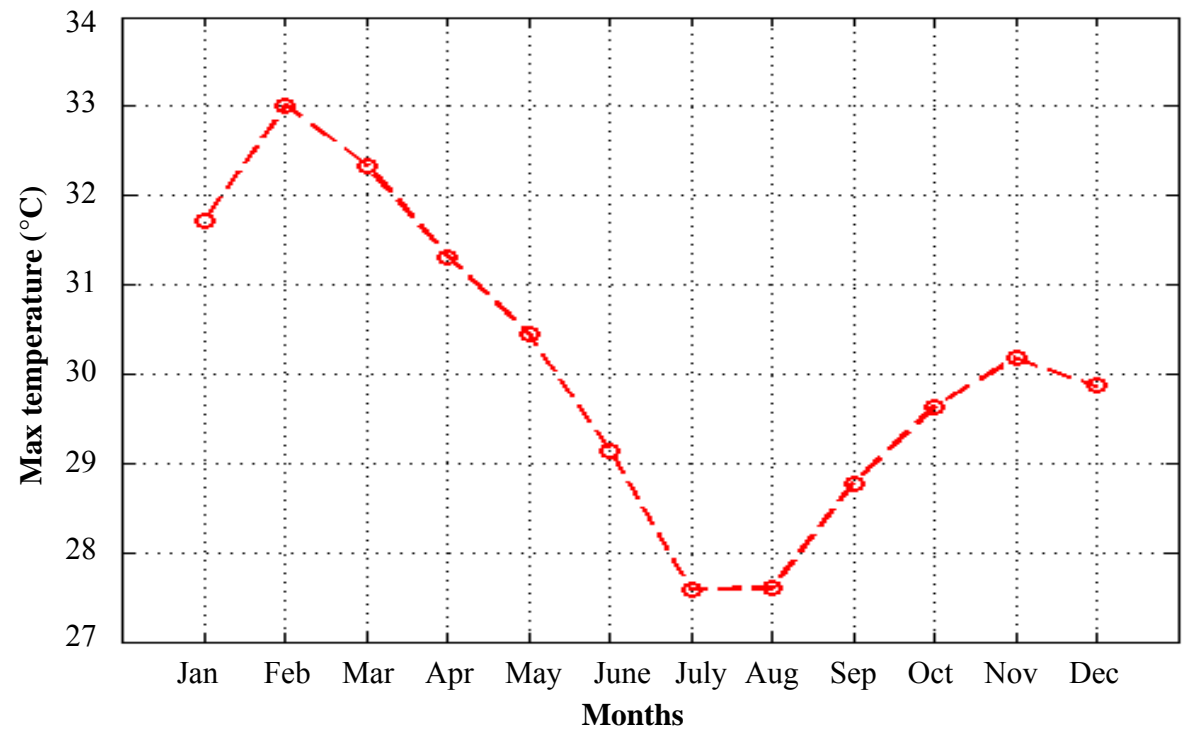

Fig. 11 Annual variation of the maximum temperature in 1981-2014 in N'zerekore.

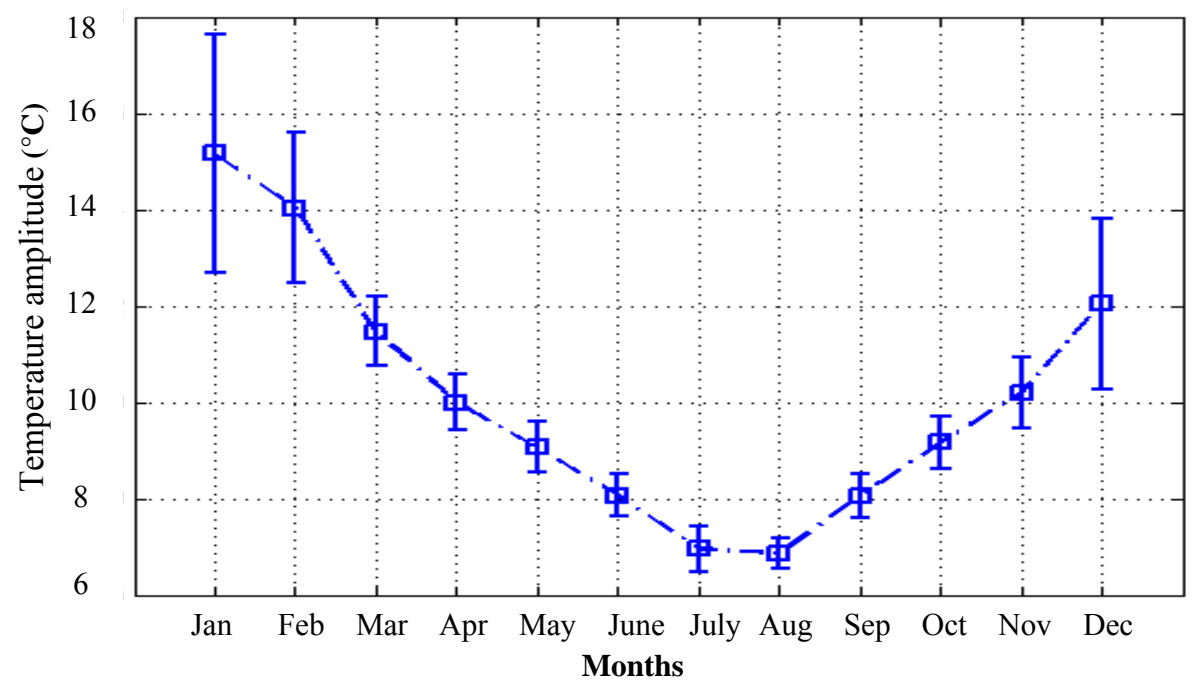

Fig. 12 Thermal amplitude of temperature in 1981-2014 in N'zerekore. 
The Intergovernmental Panel on Climate Change (IPCC) in 2007 expects the warming in the 21st century to be the greatest over land and at the highest northern latitudes. For the next two decades, a warming of about $0.2{ }^{\circ} \mathrm{C}$ per decade is projected.

However, temperatures in N'zerekore are softened by vegetation and high humidity, and very little. The annual temperature range that exceeds $33{ }^{\circ} \mathrm{C}$ is high compared to the coastal zone. The annual average is around $24{ }^{\circ} \mathrm{C}$. The minimum rarely lowers below $16^{\circ} \mathrm{C}$, accompanying heavy rains in July-August and December-January in Harmattan ${ }^{1}$. The highest temperatures are recorded late in the dry season. The maximum average is $33{ }^{\circ} \mathrm{C}$ in January, and it rarely exceed this value.

Statistical analysis of the air temperature determines the frequency of certain thresholds necessary for evaluating thermal regimes.

The annual minimum temperatures in 1981-2014 in $\mathrm{N}$ 'zerekore are between $16.5^{\circ} \mathrm{C}$ and $21.5{ }^{\circ} \mathrm{C}$. It is weaker in January and higher in May (Fig. 10). While the maximum temperatures are between $27.5{ }^{\circ} \mathrm{C}$ and $33{ }^{\circ} \mathrm{C}$. The maximum temperature is higher in dry season (February and November) and weaker in wet season (July-August) (Fig. 11). The temperature amplitude is variable in winter (December, January and February), while it varies very little in summer (Fig. 12).

Data from the ECMWF interim reanalysis (ERA) indicate that 2010 ranks as the world's second warmest year, with the difference between it and 2005 within the margin of uncertainty.

The decade of 2001-2010 is also the warmest on record. This result is confirmed with both the northern hemisphere and Africa case, where regional temperature for 2010 was the warmest year on record [16].

Temperatures over the decade averaged $0.46{ }^{\circ} \mathrm{C}$

\footnotetext{
${ }^{1}$ Harmattan is in Sahara and in Central and West Africa, a wind from the northeast, very hot during the day, cooler in night, very dry, often dusty. It is a continental trade wind. It blows South-West from the Sahara and affects the Gulf of Guinea in the winter, between late November and mid-March.
}

above the 1961-1990 mean, $0.21{ }^{\circ} \mathrm{C}$ warmer than the previous record in decade of 1991-2000. In turn, 1991-2000 is warmer than previous decades, consistent with a long-term warming trend.

\subsection{Evaporation}

Water vapor is the most important greenhouse gas. However, because of the abundance of water, there is virtually no direct human influence on the amount of the atmosphere. In contrast, human activities alter the concentrations of greenhouse gases, such as $\mathrm{CO}_{2}$, methane, $\mathrm{N}_{2} \mathrm{O}$ and the release of chlorofluorocarbons (CFCs). As the concentrations of greenhouse gases in the atmosphere increase, the amount of solar energy absorbed at the surface remains almost unchanged, but the lower levels of the atmosphere absorb more outgoing terrestrial radiation.

Evaporation is a physical process by which the water passes from liquid state to vapor state. But for this phase, change can take place, there must be energy availability (heat or kinetic) and water. In nature, evaporation is related to solar radiation, wind and moisture deficit.

From 1961 to 2014, N'zerekore records a total evaporation of 40,282.2 $\mathrm{mm}$. A total annual maximum evaporation of $1,139 \mathrm{~mm}$ is recorded in 2014 and a minimum of $498.2 \mathrm{~mm}$ in 1963 . The annual evaporation average is $746 \mathrm{~mm} /$ year.

A monthly maximum of $219 \mathrm{~mm}$ is recorded in January 2007 and a minimum of $15.3 \mathrm{~mm}$ in August 1964. These are the values of potential evaporation calculated according to Penman formula.

From 1961 to 2014, evaporation is increasing since 1981, and in the years, it can cover November to December and January to April (Fig. 13). Since 2002, the evaporation value below $40 \mathrm{~mm}$ is not observed.

\subsection{Storms Frequency}

The WMO precisely defines the storm like a meteor, characterized by two consecutive audible and thunderous sounds of the earth's surface. 
Storm clouds develop from cumulonimbus clouds or cumulonimbus clusters, which can contain hundreds of thousands tons of water, hail and small ice crystals. They essentially differ from rain clouds, first by the sheer scale of their vertical and horizontal expansion, but especially by the fact that they give rise to electrical phenomena.

The considerable vertical extent of storm clouds, which often reach the tropopause (between $8 \mathrm{~km}$ and $16 \mathrm{~km}$ altitude depending on latitude) and sometimes even exceeds, generally requires for their unstable air masses development, wet and hot so strong temperature gradients over significant thicknesses.

These clouds can arise in an unstable warm air mass and homogeneous. Then, they develop sporadically, but often preferred, during afternoon over places where topography (mountains) or the soil (e.g., a densely built) favor overheated masses air in the lower layers and therefore their ascent.

In this study, 1987 is the year in which the maximum of storm was observed in the series (Fig. 14). The annual average of storm distribution shows two pics with 22 and 24 times in May and October, respectively. Two absolute maximum values

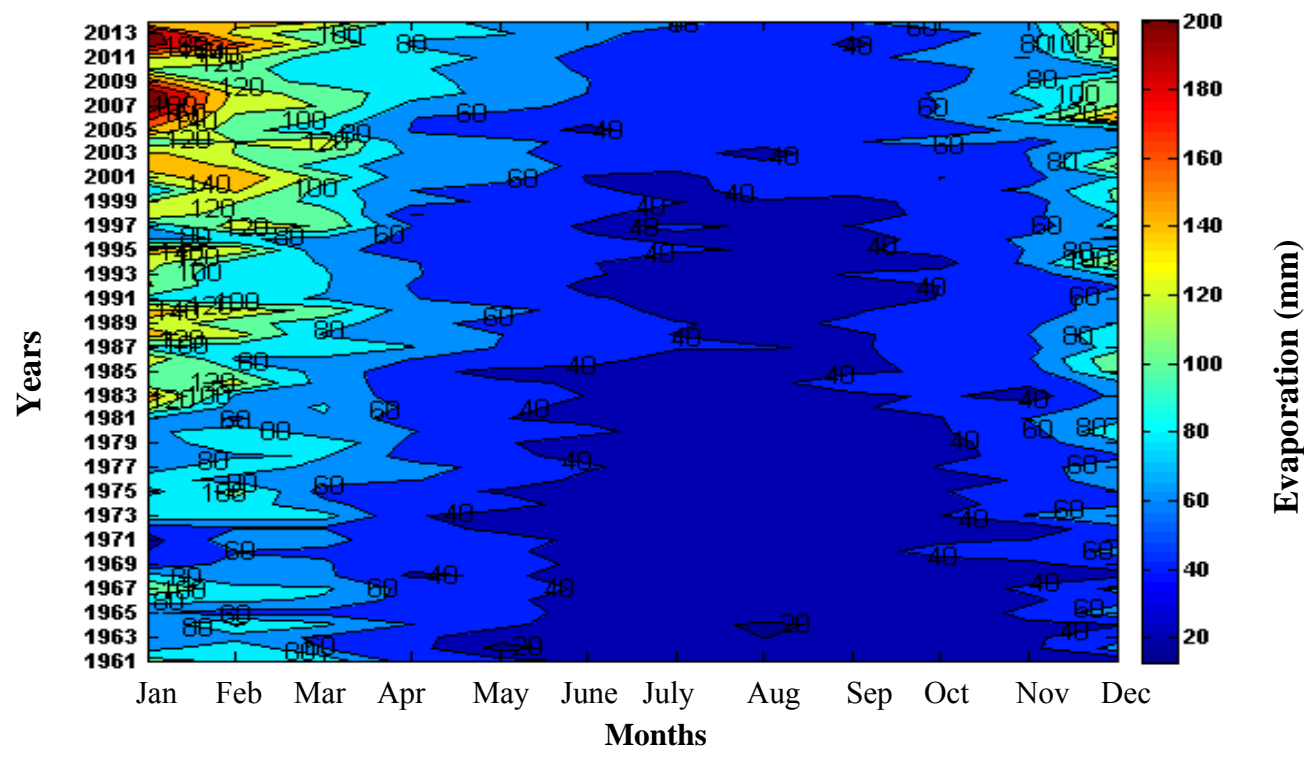

Fig. 13 Climatology of evaporation (1961-2014) in N'zerekore.

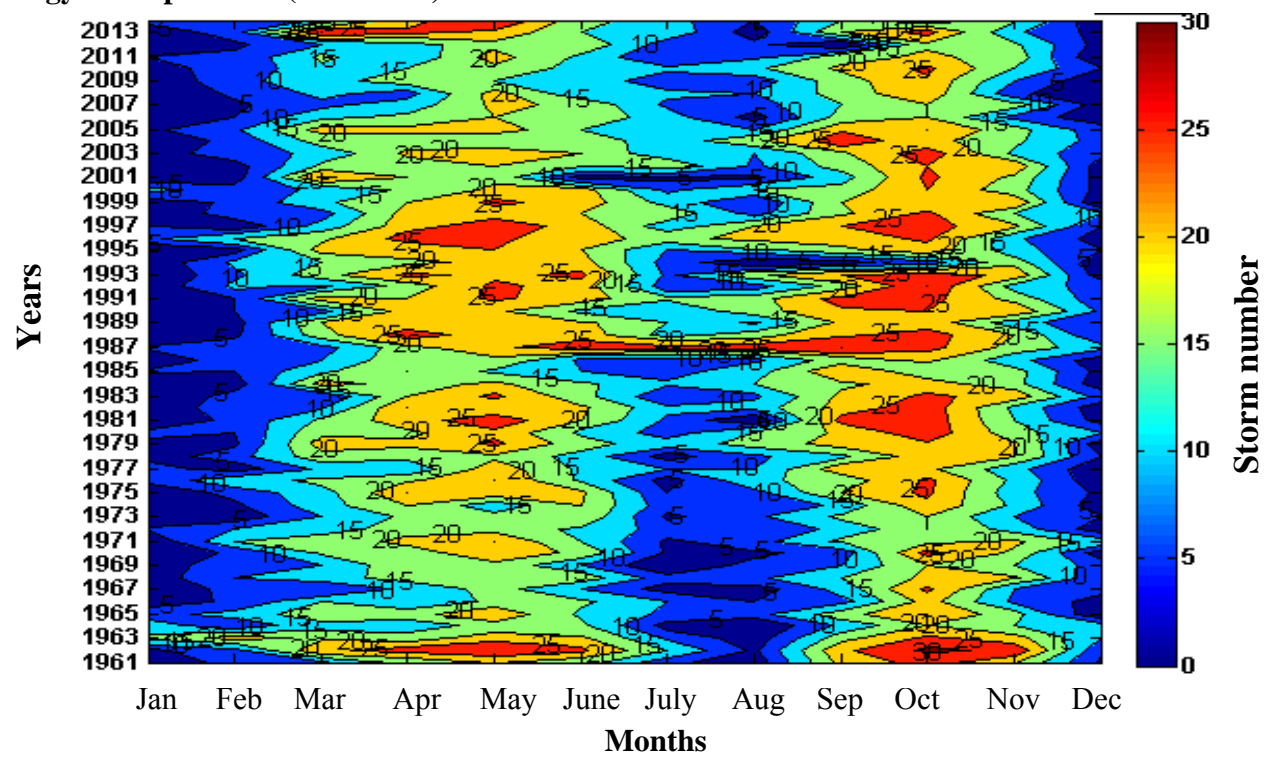

Fig. 14 Climatology of storm (1961-2014) in N'zerekore. 
(29 and 31) are also observed in the same months (May and October), respectively. This result is exactly consistent with other one. The average annual stormy and rainy days are determined for each site. An annual average for rainy and stormy days of 132 and 137 is found. The peak occurrence of stormy or rainy day is observed at N'zerekore [17]. It shows that storms are more frequent and strong at the end of wet season than the beginning.

\subsection{Wind Speed and Direction}

Wind is air movement over ground surface. There is a direct consequence of the inequality of the ground pressure between two areas. Wind is characterized by direction and strength. Measuring the wind direction using the wind vane and represents the wind direction from the north. It is expressed in degrees or pink letters $\left(360^{\circ}\right.$ or north, $270^{\circ}$ or west). The anemometer measures the wind speed and weather vane shows wind direction. Two units are used, and the only logic is obviously the speed in meters per second $(\mathrm{m} / \mathrm{s})$. But in aviation, knots ( $\mathrm{kt}$ ) and foot (ft) are also used to characterize the wind speed.

During the year, the prevailing wind in N'zerekore is westerly (W) with an average speed of $2.6 \mathrm{~m} / \mathrm{s}$ (Fig. 15). But during the day, the season, which often dominates with light winds at night being quiet, strong winds are observable at the beginning and end of the rainy season. These strong winds often accompany thunderstorms. It is believed that the action of the harmattan is sensitive to this region and this action tends to increase as the forest is degraded.

\subsection{Variability of Agroclimatic Parameters}

Seasonal weather and climate variations have a significant impact on society, because of their effects on water resources, environment and health, and more directly on agriculture and food security. These variations can significantly diminish agricultural yields.

The components of the largest rainfall regime in agricultural applications field are: start dates, end dates and lengths of growing seasons, the distribution of rainfall events (dry sequences, the number of rainy days) during the crop season, and seasonal totals.

\subsubsection{Annual Total Rainfall}

The standardized anomalies of annual totals rainfall (Fig. 16) indicate three major periods: a wet period (surplus) from 1931 to 1977, a deficit period (dry) from 1978 to 1993 and interannual variability period from 1994 to 2014. Annual and seasonal total rainfall decreases with slopes (straight line regression) of -0.891 and -0.532 , respectively. Annual rainfall totals have a downward trend with slopes (linear regression of -0.89).

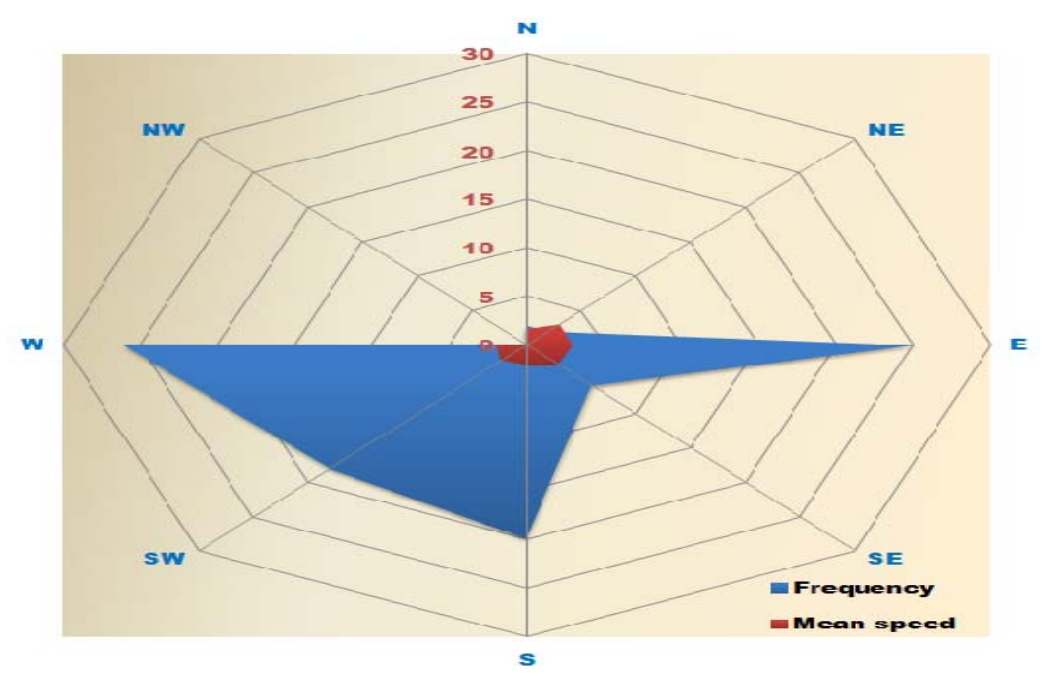

Fig. 15 Wind variability (1961-2014) in N'zerekore.

W: westerly; S: southerly; E: easterly; N: northerly; SW: southwester; SE: southeaster; NE: northeaster; NW: northwester. 


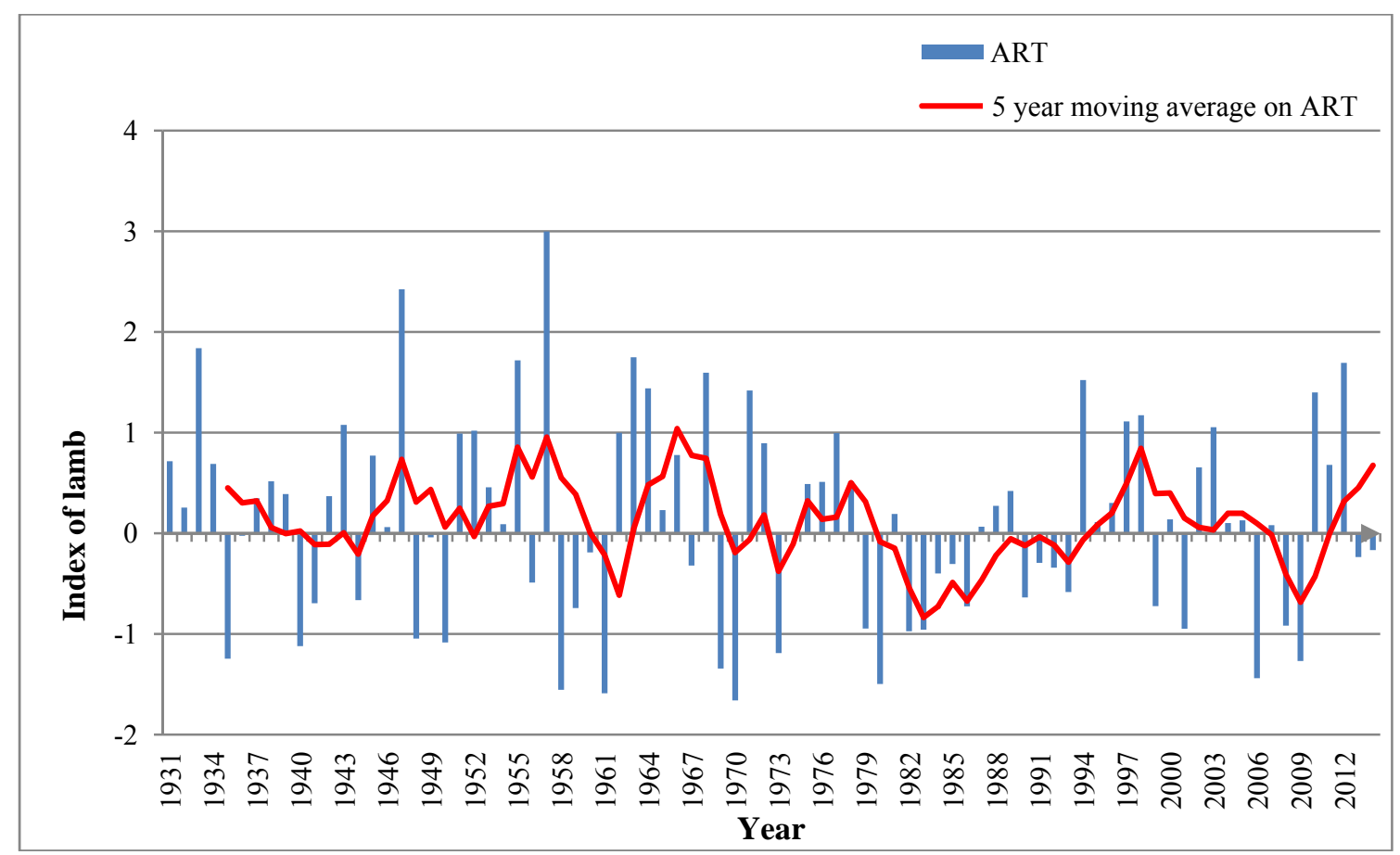

Fig. 16 Annual rainfall total (ART) in 1931-2011 in N'zerekore.

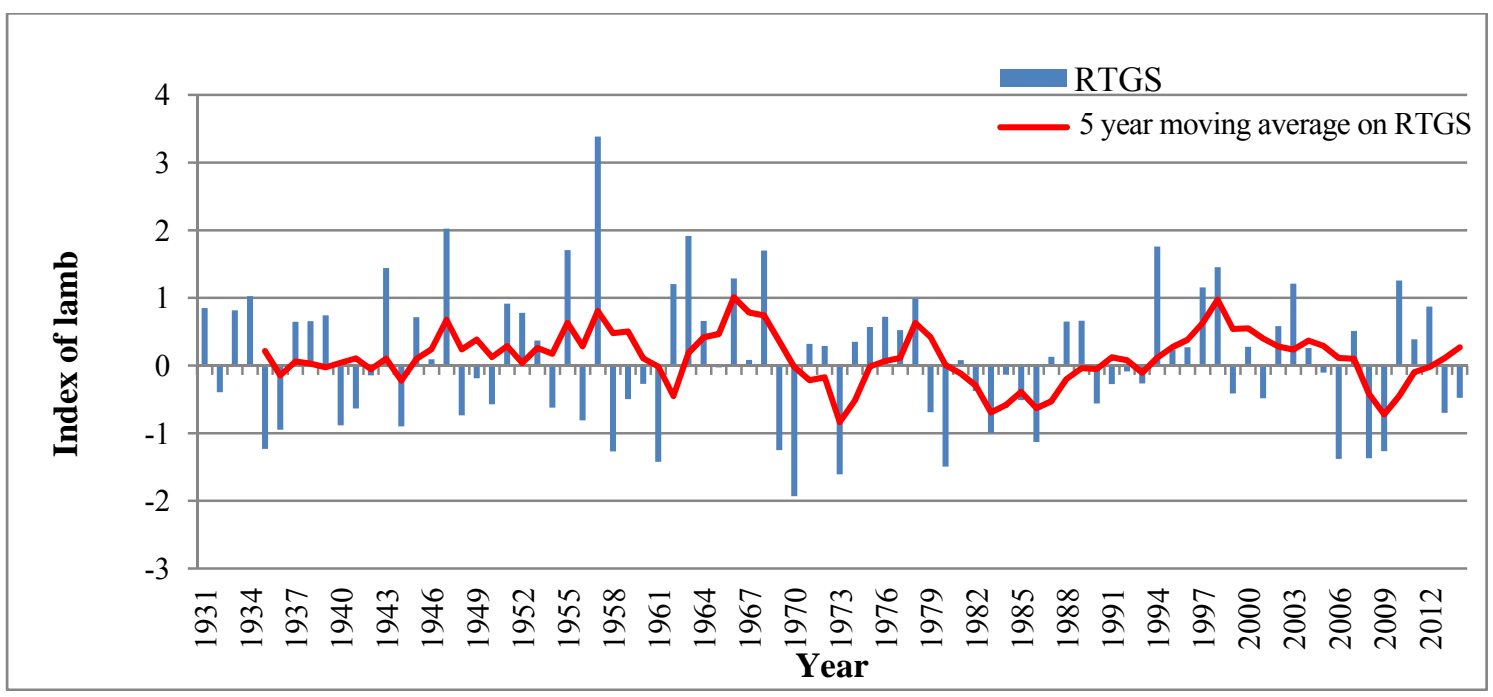

Fig. 17 Growing season rainfall total (RTGS) in 1931-2009 in N'zerekore.

\subsubsection{Rainfall Total of Growing Season}

The standardized anomalies of rainfall total of growing season (Fig. 17) indicate three major periods: a wet period (surplus) from 1931 to 1977, a deficit period (dry) from 1978 to 1993 and interannual variability period (1994-2014). Seasonal rainfall totals have a downward trend with slopes (linear regression of -0.532). Thus, there are, on the one hand, the excess period 1950-1969, and inconversely, the 1970-2000 period which is generally dried.

\subsubsection{Growing Season Beginning Date}

For southern observatories in Guinea (area below $8^{\circ}$ $\mathrm{N}$ latitude), the growing season begins after March 15, from which a total rainfall at least $20 \mathrm{~mm}$ is recorded in 1-3 consecutive days without dry period exceeding $10 \mathrm{~d}$ in $30 \mathrm{~d}$ [1]. Then, the rain installation date and the rainy season length are two essential parameters for agriculture, since they determine, on the one hand 
the sowing date, and on the other hand the duration of the period during which the crops can benefit from rainfall, regardless of water-supply conditions of that period.

For northern observatories in Guinea (area under $8^{\circ}$ $\mathrm{N}$ latitude), the growing season begins after May 1, from which a total rainfall at least $20 \mathrm{~mm}$ is recorded in 1-3 consecutive days without dry period exceeding $10 \mathrm{~d}$ in $30 \mathrm{~d}$ follow [1].

The starting dates of growing season are equally positive slope at 0.038 (Fig. 18). This value is positive, meaning that the growing season starting dates deviate increasingly late. In the series studied, growing season beginning dates are between the 75th and the 119th day of the year, i.e., between March 15 and April 28. Early start dates of the growing season are registered before March 15 (the 79th day of the year) before the 33 rd percentile ${ }^{2}$. As for late starts, they are recorded after March 26 (the 86th day of the year), after the 66th percentile. The period between the 33rd and 66th percentile is the average period of the growing season start in N'zerekore.

The analysis shows also that $36 \%$ of years in the studied series have an early start of growing season, $35 \%$ of years have had a normal start and $29 \%$ of years have had a late start. In the wet period (1931-1977), 40\% of the years have had an early start of growing season against $28 \%$ late start. However, in the dry period and rainfall variability period, there are, respectively, $25 \%$ and $33 \%$ of early start of planting season against $50 \%$ and $19 \%$ of late start.

Compared to the reference period, there are two periods of early start growing season (standard negative anomalies): 1931-1944 and 1955-1976, two periods of late start (standard positive anomalies): 1945-1954 and 1977-1993, and a start-up period more or less variable that goes from 1994 to 2014 .

\footnotetext{
${ }^{2}$ A percentile (or a centile) is a measure used in statistics indicating the value below which a given percentage of observations in a group of observations fall. For example, the 33 rd percentile is the value (or score) below which $33 \%$ of the observations may be found.
}

\subsubsection{Growing Season End Date}

In the series studied, the length of the growing season is between October 15 (the 289th day of the year) and December 20 (the 355th day of the year) (Fig. 19). It was found that in Togo, in the rain season, growing season takes end in October [18]. Early end for the growing season is registered before November 10 (the 315th day of the year), before the 33rd percentile. As for later use, it is recorded after November 22 (the 327th day of the year), after the 66 th percentile. The period between 33rd and 66th percentile is considered average period for the growing season end in N'zerekore.

But between 1931 and 2014, 36\% of growing seasons had an early end, 19\% were normal and $45 \%$ were delayed. Compared to the reference period 1961-1990, analysis of standard indexes shows a late period end (positive standard index) of the cropping season from 1931 to 1969 , an early end period (negative index) of the growing season from 1970 to 1989 and a fine variability period of growing season.

There is also a regression coefficient (slope) of the linear regression of the end dates of the agricultural season of 1931-2014 equal to -0.0462 . This value is negative, meaning that the end of growing season becomes from time to time early.

In the so-called wet period (1931-1977), 32\% of the crop season have an early end against $49 \%$ of later end. As for dry periods (1978-1993) and rainfall variability (1993-2014), they record $38 \%$ and $43 \%$ of early end growing season against $50 \%$ and $33 \%$ of late end season. After September 1, a ground capable to containing $70 \mathrm{~mm}$ available water is completely exhausted by daily loss of $5 \mathrm{~mm}$ evapotranspiration.

The total amount of rainfall was registered between the date of beginning of the season and the end date of the season. The annual total rainfall was recorded from January 1 to December 31.

In order to highlight the main features of change and variability in rainfall patterns and its components to strong intra seasonal agricultural impacts, the 


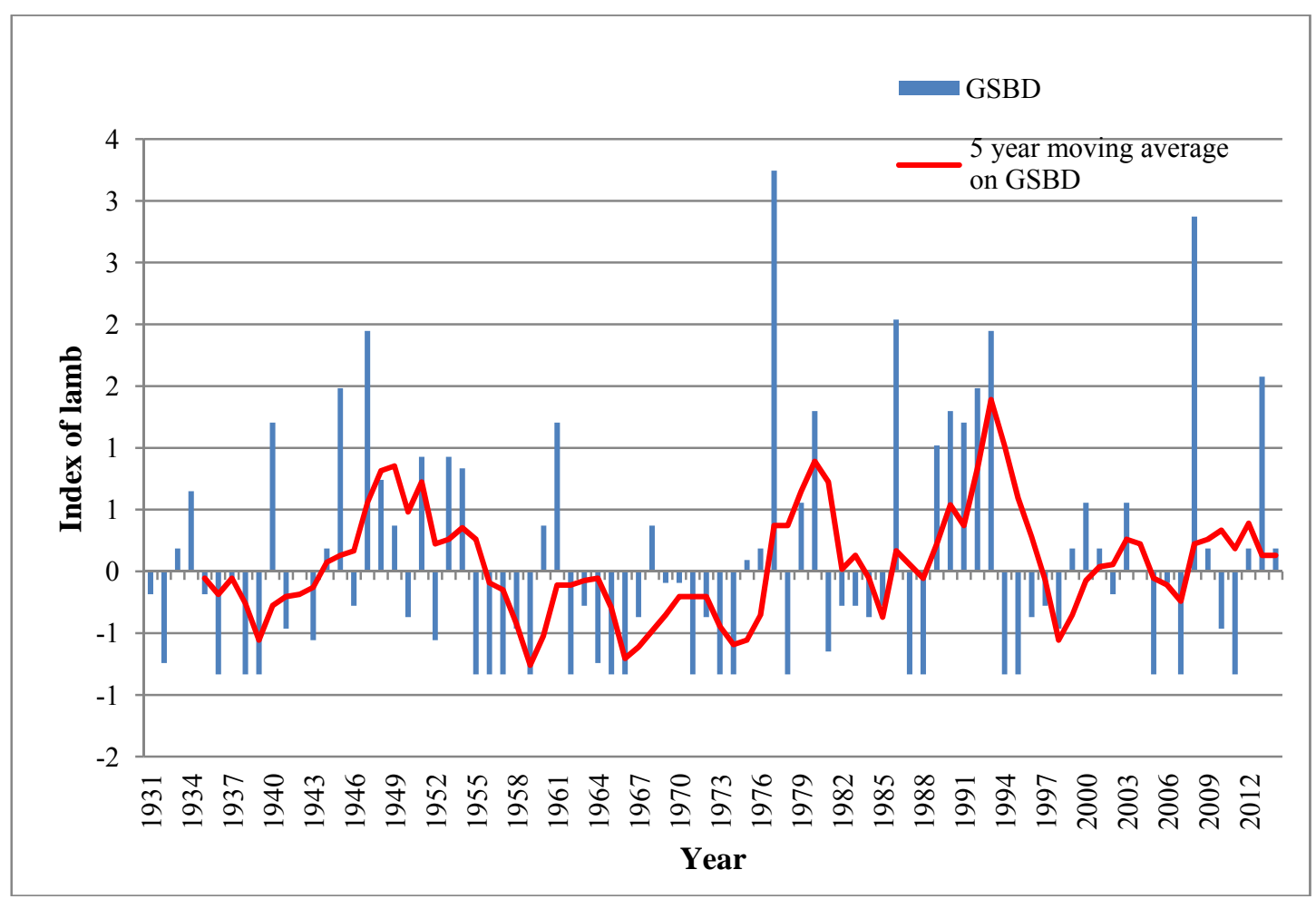

Fig. 18 Growing season beginning date (GSBD).

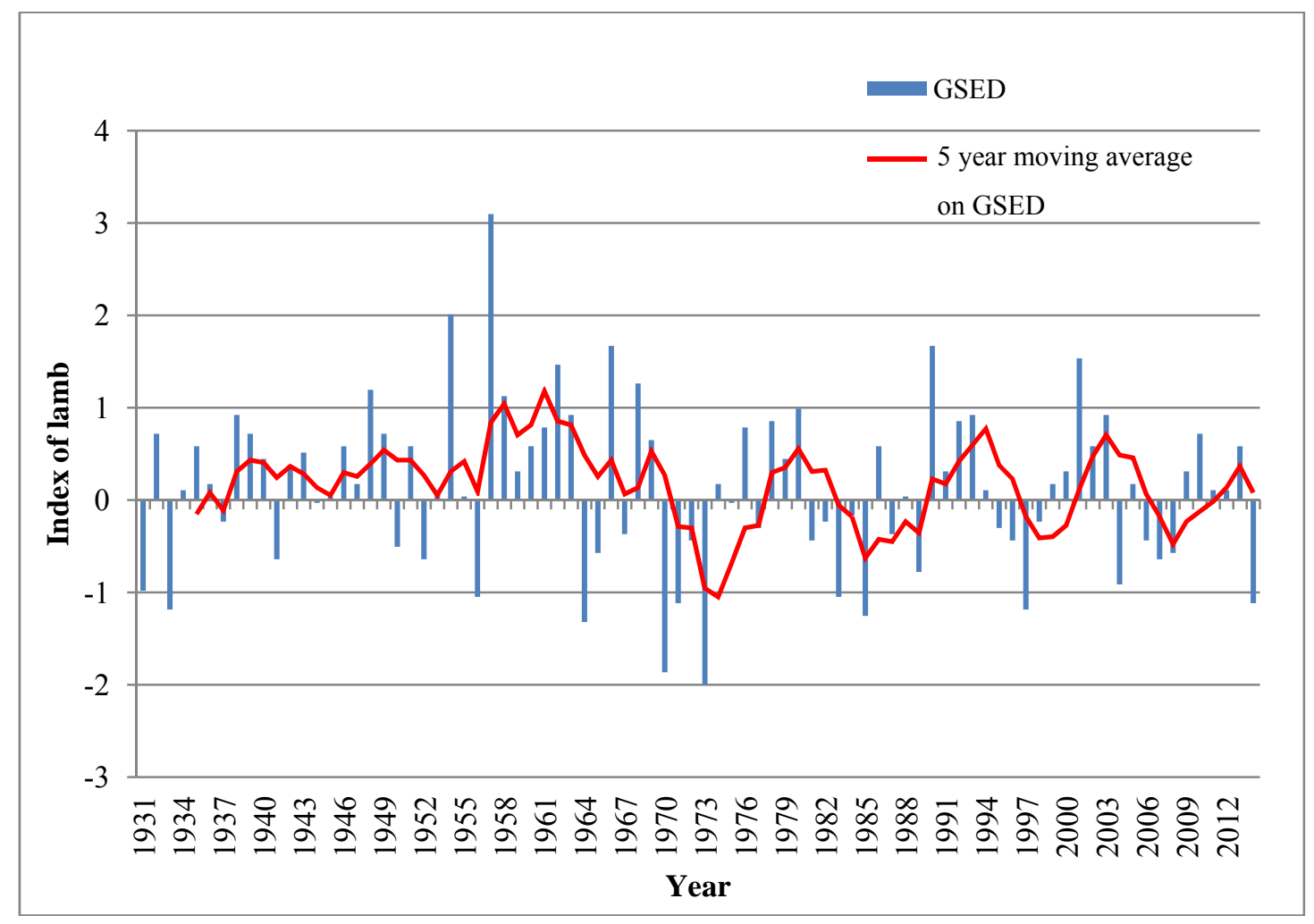

Fig. 19 Growing season end date (GSED). 
climatological normal of 1961-1990 period, according to World Meteorological Organization, is used in studies of variability and climate change [19-21]. Thus, this normal period was considered in the statistical analysis [22] as Eq. (1):

$$
\text { Index of Lamb } I=(X i-X) / \sigma
$$

where, $I$ is the standardized anomaly (index Lamb), $X i$ is the variable (rain) of interest for the time $(i), X$ is the average of the reference period considered, $\sigma$ is the standard deviation of the reference period.

\subsubsection{Growing Season Length}

Growing season length is the difference of growing season end date and growing season beginning date.

From 1931-2014, the lengths of the growing season range from $195 \mathrm{~d}$ to $289 \mathrm{~d}$, for 6-10 months (Fig. 20). Analyses show a shortening of the overall length of growing seasons due to late start and early end of growing seasons. The linear regression line of the growing season lengths of the series studied gives a coefficient of regressions of -0.100 , meaning the seasons becoming shorter.

Compared with the reference 1961-1990, the length of the growing season is longer in the period of 1931-1969 than the average of the reference period
1961-1990. From 1970 to 2000, growing seasons are in general short than the average of the reference period. The period from 2001 to 2014 presents a particular situation: alternating short and long growing seasons without any periodicity.

\subsubsection{Dry Sequences}

The number of consecutive dry days during $50 \mathrm{~d}$ after the beginning of the growing season ranges from $3 \mathrm{~d}$ to $13 \mathrm{~d}$. The longest dry sequences after the growing season start date are observed during the dry period 1977-1994.

In general, the longest dry sequences after the growing season start become shorter with a negative regression coefficient of -0.0078 . As for the number of consecutive dry days, the longer of the period takes into account the critical phases of heading-flowering and ripening of crops varies between $4 \mathrm{~d}$ and $29 \mathrm{~d}$. The longer sequences have been recorded during the dry period or deficit from 1977 to 1994.

\subsubsection{Dry Sequences Periods at the Growing} Season Beginning

As the sequences of the growing season start, the long sequences are recorded in critical to heading-flowering and maturation phases are becoming

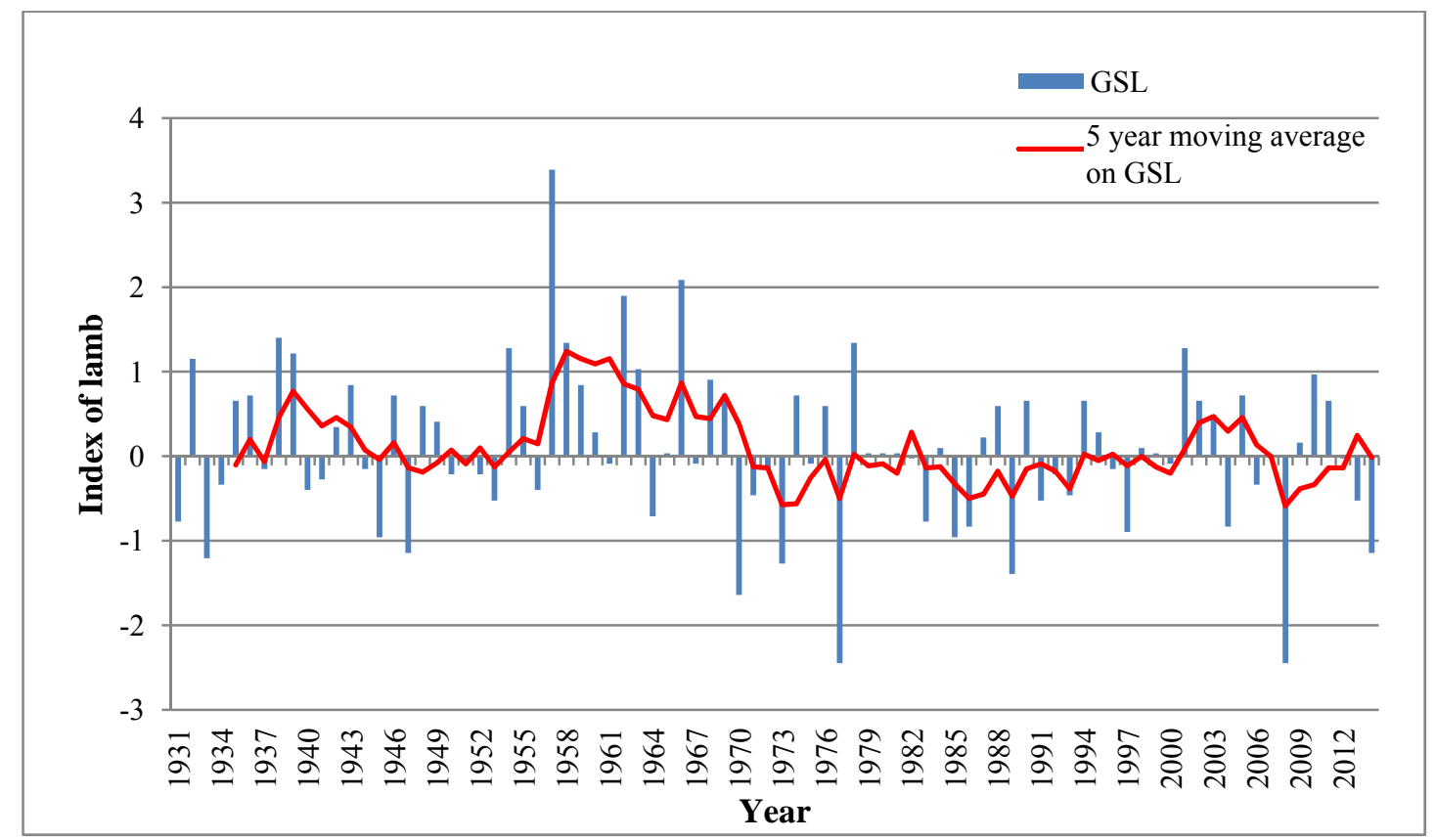

Fig. 20 Growing season length (GSL). 


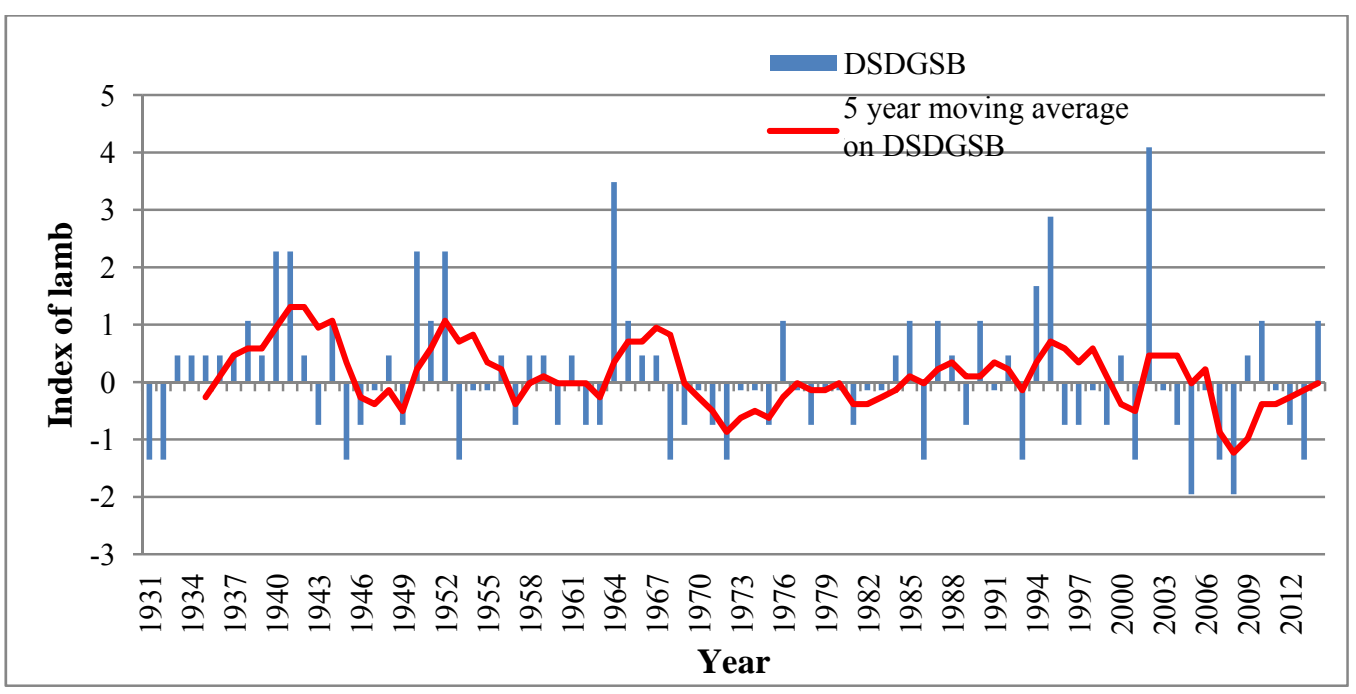

Fig. 21 Dry sequences at growing season beginning (DSDGSB).

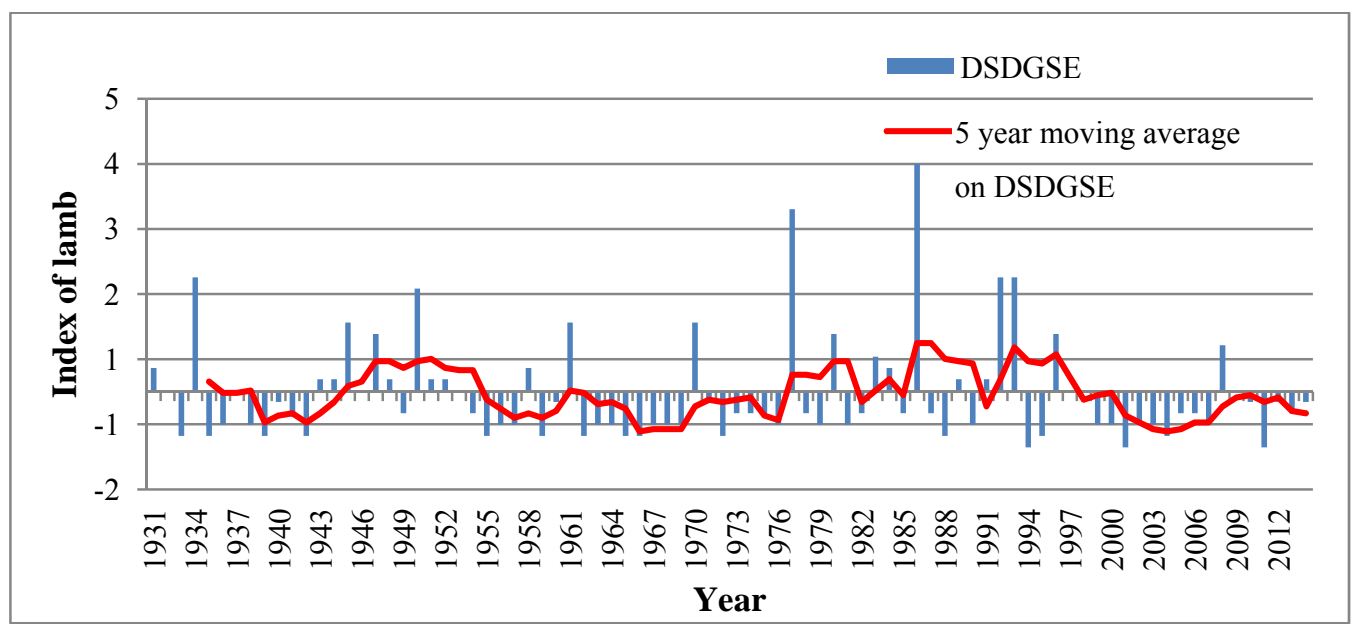

Fig. 22 Dry sequence at the growing season end (DSDGSE).

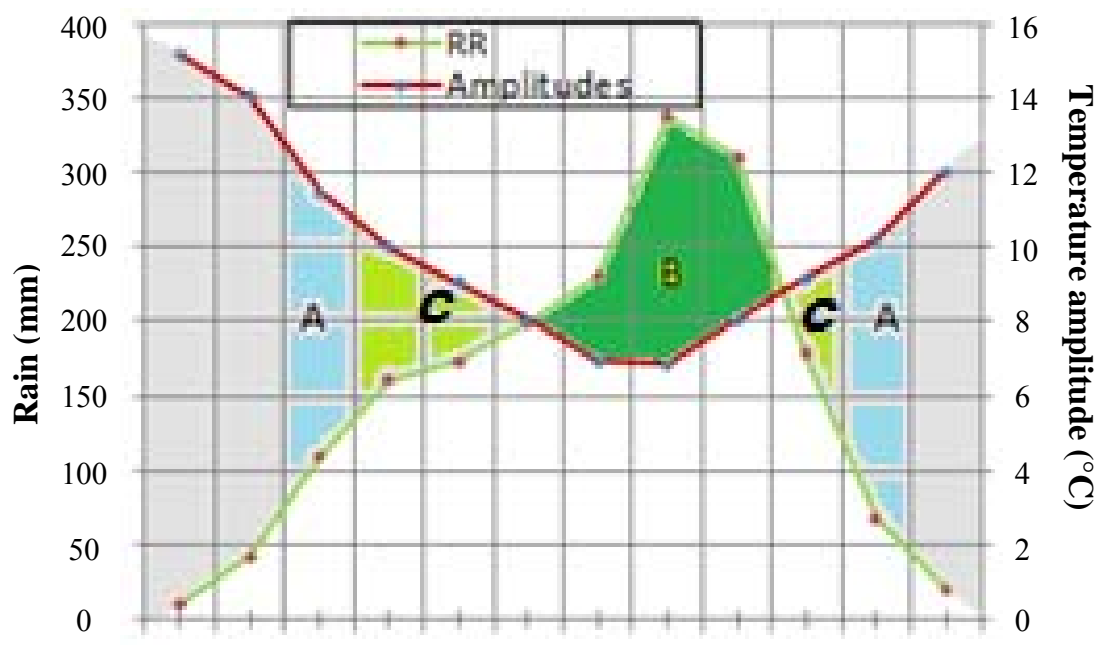

Jan Feb Mar Apr May June July Aug Sep Oct Nov Dec Months

Fig. 23 Agricultural calendar. 
shorter with a negative regression coefficient of -0.0101 .

The number of longest consecutive dry days during $50 \mathrm{~d}$ after agricultural season start date is considered as dry sequences periods at the growing season beginning. One day is considered as rainy day when the total amount of rainfall is greater than or equal to 1 $\mathrm{mm}$. They get by counting the number of consecutive days without rain, i.e., the days between two rainy days (Fig. 21).

3.6.6.2 Dry Sequences Periods at the Growing Season End

The longest dry sequence in the season, that is to say the period taking into account the critical flowering-heading stages and maturation of crops, is calculated from the 50th day after the date of season beginning until the end date. For this purpose, $50 \mathrm{~d}$ was subtracted from the average length of the growing season (GSL_mean), i.e., GSL_mean - 50, and in the end, the length of the dry sequences was determined over the remaining period of the average length of the season (GSL_mean - 50) from the $50 \mathrm{~d}$ of start date of the season (Fig. 22).

\subsection{Agricultural Calendar}

An important instrument in developing sustainable agriculture technologies is systems analysis [23]. The area between the amplitude and rain curves (C) is wet, and it lasts in April, May, June and October. Meanwhile, plants' water needs are fully covered (Fig. 23). March and November periods match the pre- and post-wet periods (A). They are called agricultural fields preparation or protection period, according to the considered moment. In this period, a sufficient quantity of stored heat in the ground helps of grain germination.

The area between the thermal amplitude and precipitations curves (B) corresponds to the very wet period. It takes about three months (July, August and September). In this moment, water excess in soil is recorded and plants can not use it; groundwater aquifers are fed, consequently waterways are filled and floodplains are overwhelmed (floods cases). This period should be avoided to make the harvest because of the risk of diseases spreading and drying difficulties associated with high humidity and frequent rainfall and continuous.

\section{Conclusions}

Analysis of climate variability in Nzerekore shows a variability of meteorological parameters as well as the disruption of the beginning and the end of the growing season. The analysis of precipitations variability and the impact of warm and cold water events on coastal precipitation for the period of 1931-2014 shows that agro-climatic parameters in N'zerekore have high variability. From 1931 to 2014, three major periods can be distinguished: a wet period from 1931 to 1977 , a dry period from 1978 to 1994 and rainfall variability from 1995 to 2014 . That is a direct consequence of climate change for which mitigation is necessary.

The total rainfall for the growing season is becoming weaker. Evaporation is increasing at two dimensions: interannual and annual; that is a direct consequence of climate change and forest degradation in this region. The beginning of growing season becomes late, while the end of growing seasons is becoming increasingly early, hence the shortening of growing season length. As for the longest dry sequences, they become shorter. Increases in the amount of precipitations are very likely in high latitudes, while decreases are likely in most subtropical land regions. Drought-affected areas will likely increase in extent. It is very likely that hot extremes, heat waves and heavy precipitations events will continue to become more frequent. Given these projections of future climate change, there will be increased land degradation owing to droughts and increased soil erosion owing to heavy rainfall events. Climate variability has thus played a significant role in undermining economic development in Zambia in 
the past and will continue to do so in the future.

Further analyses of meteorological parameters trends relationship and their possible causes are needed and should be subject to future paper.

Thus, climate change may further exacerbate the negative consequences of climate variability. There is considerable scope and incentive, therefore, to invest in irrigation and water management practices aimed at mitigating the adverse effects of both climate variability and climate change on Guinea's economic development. Climate change is a continuing problem with the most significant warming still to come.

\section{References}

[1] Barry, A. B., and Sivakumar, M. V. K. 1997. "Agroclimatology of West Africa: Guinea." Accessed April, 2015. http://agris.fao.org/agris-search/search.do?recordID=XF2 015043248. (in French)

[2] CEDEAO-CSAO/OCDE. 2008. "Climate and Climate Changes." Environment Series, Ouest Africa Regional Integration Atlas. Accessed January, 2008. https://www.oecd.org/fr/csao/publications/40121057.pdf. (in French)

[3] Brown, O., and Crawford, A. 2007. "Climate Change: A New Threat to Stability in West Africa? Evidence from Ghana and Burkina Faso." African Security Review 17 (3): 39-57.

[4] Canadian Climate Impacts and Adaptation Research Network (C-CIARN). 2001. "Risks and Opportunities from Climate Change for the Agricultural Sector." Final Report of C-CIARN, Farming Systems Research, University of Guelph, Guelph, Ontario. Accessed March, 2001. http://www.c-ciarn.uoguelph.ca/documents/2001_ Workshop_Report.pdf.

[5] Beavogui, M. 2012. "Impacts of Climate Change on the Cultivation of Upland Rice in Upper Guinea and Proposed Adaptation Strategies." Master thesis, Agrhymet Regional Centre, Niamey, Niger. (in French)

[6] Ministry of Agriculture, Livestock, Environment, Water and Forests. 2007. "National Action Plan for Adaptation to Climate Change of the Republic of Guinea." Accessed July, 2007. http://unfccc.int/resource/docs/napa/gin01f.pdf. (in French)

[7] Beavogui, F., Cisse, S., and Pedelahore, P. 1991. Zoning Upper Guinea. Kankan: Guinea Agricultural Research Center (Bordo). (in French)

[8] World Meteorological Organization (WMO). 2011. "Knowing Climate for Action: A Global Framework for
Climate Services to Strengthen the Position of the Most Vulnerable.” OMM No. 1066. Accessed May, 2011. https://library.wmo.int/pmb_ged/wmo_1066_fr.pdf. (in French)

[9] Kourouma, J. M. 2015. "Study of the Vulnerability of Agriculture to Climate Change in Forest Guinea: For Farmers in Peri-urban Rural Areas of the Municipality of N'Zérékoré South-Eastern Guinea." Master thesis, Centre Regional Agrhymet, Niamey, Niger. (in French)

[10] Thurlow, J., Zhu, T. J., and Diao, X. S. 2009. The Impact of Climate Variability and Change on Economic Growth and Poverty in Zambia. Washington: International Food Policy Research Institute.

[11] Traoré, A. F., Diallo, M. L., Bamba, Z., and Mara, F. 2002. "Initial Communication in Guinea to the Framework Convention United Nations Change Climate." Ministry of Mining, Geology and Environment. Accessed August, 2002. http://unfecc.int/resource/docs/natc/guinc1.pdf. (in French)

[12] Aguilar, A., Aziz Barry, A., Brunet, M., Ekang, L., Fernandes, A., Massoukina, M., Mbah, J., Mhanda, A., Do Nascimento, D. J., Peterson, T. C., Thamba Umba, O., Tomou, M., and Zhang, X. 2009. "Changes in Temperature and Precipitation Extremes in Western Central Africa, Guinea Conakry and Zimbabwe, 1955-2006." J. Geophys. Res. Vol. 14. doi:10.1029/2008JD011010.

[13] Bangoura, Y. 2007. "Use of Climate Information for Agriculture, Forestry and Livestock in Guinea." World Agro-meteorological Information Service. Accessed February 4, 2013 http://www.wamis.org/agm/pubs/agm7/Bangoura.pdf. (in French)

[14] Lutz, K., Jacobeit, J., and Rathmann, J. 2015. "Atlantic Warm and Cold Water Events and Impact on African West Coast Precipitation.” Int. J. Climatology 35 (1): 128-41.

[15] World Meteorological Organization (WMO). 2003, "Climate Change: Impacts on Global Agriculture." Accessed February 4, 2013. http://www.wamis.org/agm /pubs/brochures/climatechange_issue_brief.pdf.

[16] World Meteorological Organization (WMO). 2011. "WMO Statement on the Status of the Global Climate in 2010." WMO No. 1074. Accessed September, 2011. http:/www.wmo.int/pages/prog/wcp/wcdmp/documents/ 1074 en.pdf.

[17] Béavogui, K., Badiane, D., Sall, S. M., and Diaby, I. 2011. "Climatological Approach Rainfall PhenomenonStormy in Guinea." Sciences Journal for l'Ingénieur 13: 71-7.

[18] Adewi, E., Badameli, K. M. S., and Dubreuil, V. 2010. "Evolution of Rainy Seasons Potentially Useful in Togo 
from 1950 to 2000." Climatologie 7: 89-107. (in French)

[19] Sarr, B., Traore, S. B., and Salack, S. 2006. Climate Change Index Evaluation on Cereal Crop Yields in Sudano-Sahelian Africa. Niamey: Regional Center of Agrhymet. (in French)

[20] Ly, M., Traore, S. B., Alhassane, A., and Sarr, B. 2013: "Evolution of Some Observed Climate Extremes in the West African Sahel." Weather and Climate Extremes 1: 19-25.

[21] Berg, A., Noblet-Ducoudre, N., Sultan, B., Lengaigne, M., and Guimberteau, M. 2013. "Projections of Climate
Change Impacts on Potential C4 Crop Productivity over Tropical Regions." Agricultural and Forest Meteorology 170: 89-102.

[22] Lamb, P. J. 1982. "Persistence of Sub-Saharan Drought." Nature 299: 46-8.

[23] Ford, F. B., and Kanematsu, E. T. 1997. "Methods to Transform Basic Knowledge into Operational Techniques and to Adapt Operational Techniques for Use Elsewhere." In Weather/Climate and Sustainable Agricultural Production and Protection. Geneva, Switzerland: World Meteorological Organization (WMO), 67-90. 